\title{
La política criminal securitaria en la reforma penal de 2010*
}

\author{
Juan Ignacio Echano Basaldua \\ Catedrático de Derecho penal \\ Universidad de Deusto
}

Recibido: 12.11 .2010

Aceptado: 23.11 .2010

\begin{abstract}
Resumen: La seguridad ciudadana constituye el objeto de la política criminal que ha modulado el Derecho penal español fruto de las reformas habidas, sobre todo, a partir de 2003. Pero la intensificación de la intervención penal y la flexibilización de las garantías que se ha producido de su mano, no se deben a un incremento de la criminalidad sino a un cambio en la percepción de la misma y en la valoración de que es objeto. Sus manifestaciones en la reforma de 2010 se producen sobre todo en algunos grupos de delitos, en los que se hace patente un Derecho penal cuyas penas pretenden en mayor medida la prevención general positiva (respuesta a la alarma social), la intimidación y la neutralización del peligro que representan los infractores, que su resocialización; un Derecho penal que, por ello, se escora peligrosamente hacia un derecho penal de peligrosidad, un derecho penal de autor. Semejante deriva se hace acreedora de una severa crítica, ya que el recurso prácticamente exclusivo a la pena de prisión, el endurecimiento de esta en su duración y régimen de cumplimiento, el incremento desorbitado del número de reclusos, la limitación en la vigencia de principios penales básicos, dificultan de forma importante la legitimación de tales medidas conforme a las pautas de un estado social y democrático de Derecho.
\end{abstract}

Palabras clave: política criminal securitaria, seguridad ciudadana, reforma penal de 2010

Abstract: Citizen's security constitutes the aim of the criminal policies carried out in Spain from 2003. The increasing of criminal prosecution and the flexibilization of the legal guarantees as measures implemented by these policies, are not, however, based on a rise in criminality, since they constitute on the other hand the result of a change in the perception of criminality. These measures implemented by the 2010 Criminal Code Amendment Act are specially to be found on certain groups of torts, where penalties tend mainly to a kind of positive general prevention (as an answer to the social alarm), the intimidation and the neutralization of the danger that lawbreakers represent, instead of their rehabilitation. It constitutes then a Criminal Law based on danger, a Criminal Law for enemies. This sort of evolution deserves a hard critic, since serving time in prison almost as the only penalty, the increase of the time to be served, the rise of the number of inmates and the limitation of basic criminal guarantees make extraordinarly difficult the legitimacy and compatibility of such mesures with the Rule of Law and the Welfare State model.

* El presente trabajo es una versión reelaborada de la Lección Inaugural del Curso 20102011 en la Universidad de Deusto, que dedico a José Manuel Fínez Ratón excelente jurista, compañero entrañable y, por encima de todo, hombre de bien, cuyo reciente fallecimiento nos deja una ausencia dolorosa. 
Key words: securitarian criminal policies, citizen's security, 2010 Criminal Code Amendment Act

Sumario: I. Política criminal securitaria y reformas actuales.II. Factores para su aceptación. 1. Ausencia de incremento de la criminalidad y su percepción. 2. Cambio en la valoración de la criminalidad.III. Manifestaciones en la reforma penal de 2010 (LO 5/2010). 1. Delincuencia leve reiterada de carácter patrimonial. 2. Delincuencia grave violenta, en especial, delitos sexuales y de terrorismo. 3. Criminalidad organizada, especialmente, en el marco del terrorismo.-IV. Consideraciones críticas. V Consideración final.

\section{Política criminal securitaria y reformas actuales}

El 23 de diciembre entrará en vigor la Ley Orgánica 5/2010, de 22 de junio ${ }^{1}$ ${ }^{2}$, la vigésimo quinta ${ }^{3}$ Ley Orgánica de reforma del Código Penal de $1995(i !)^{4}$,

1 La doctrina penal (DÍAZ-MAROTO Y VILLAREJO, 2010, 19; GIMBERNAT ORDEIG, 2010, 17; LUZÓN PEÑA et al., 2010, 6; MESTRE DELGADO, 2010, 11; MUÑOZ CONDE, 2010, 7) indica como fecha de entrada en vigor el día 23 de diciembre de 2010. En cambio, conforme a la doctrina de la Fiscalía General del Estado manifestada en las Circulares 1/1995, 3/1996 y 1/2000 -referidas a la entrada en vigor de la Ley del Jurado, del Código Penal y de la Ley de Responsabilidad penal de los menores-, que se remiten a la doctrina jurisprudencial -STS, Sala 3. ${ }^{\mathrm{a}}$, de 21. 12. 1987 y anteriores citadas en ella-, la entrada en vigor se produciría el día 24 de diciembre del mismo año. La discrepancia radica en la interpretación del art. $5 \mathrm{CC}$, que repercute en la forma en que se deba realizar el cómputo de los seis meses de vacatio legis. La doctrina jurisprudencial actual, si bien con alguna discrepancia, se inclina por la solución que ofrecen los autores antes citados (véase BOCOS REDONDO, 2008, 1347 ss., y las SSTS y de las AAPP que recoge). Esta misma interpretación adoptó también la FGE tras las circulares citadas en la Instrucción 5/2006.

${ }^{2}$ La reforma que culmina la presente LO se inició con el Anteproyecto aprobado por el Consejo de Ministros el 13 julio 2006, que pasó a ser el Proyecto (121/000119) de LO por la que se modifica la LO 10/1995, de 23 de noviembre del Código Penal (BOCG 15 enero 2007, núm. 119-1, págs. 1 - 36). La disolución de Las Cortes dio lugar a que el Proyecto decayera, pero en la siguiente legislatura se iniciaron de nuevo los trabajos de reforma con el Anteproyecto aprobado por el Consejo de Ministros el 13 noviembre 2008. Este Anteproyecto con distintas modificaciones llegó a ser el Proyecto (121/000052) de LO por la se modifica la LO 10/1995, de 23 de noviembre, del Código Penal (BOCG 27 noviembre 2009, núm. 52-1, págs. $1-42$ ), que superó la tramitación parlamentaria y fue aprobado definitivamente por el Senado el 9 de junio de 2010 y publicado en el BOE el 23 de junio del mismo año. Véanse ALVAREZ GARCÍA / GONZÁLEZ CUSSAC (Dirs.), 2010(a), 12 ss.; SERRANO GÓMEZ, 2010, 3 ss.

${ }^{3}$ Así la "Relación de Legislación modificadora del CP de 1995", que ofrece Código penal y legislación complementaria, 36. ${ }^{\mathrm{a}}$ ed. a cargo de J. Díaz-Maroto, Ed. Civitas / Thomson Reuters, Madrid, 2010, págs. 15 s. QUINTERO OLIVARES, 2010, 15, indica, en cambio, que es la vigésimo séptima reforma del Código y MESTRE DELGADO, 2010, 7, entiende que es la vigésimo cuarta.

${ }^{4}$ Crítico con tan frecuentes reformas se muestra MESTRE DELGADO, 2010, 7, que se refiere al "extenuante proceso de reforma", a "un proceso sucesivo e interminable de insatisfacción normativa". Críticos también GONZÁLEZ CUSSAC, 2010, 39, que habla de "reforma permanente", y QUINTERO OLIVARES, 2010,15 ss., que recuerda que de pro- 
"reforma de hondo calado"5 como hace patente un dato que es meramente cuantitativo, pero revelador: afecta a más de 150 artículos ${ }^{6}$, es decir, al $25 \%$ del CP. Esta reforma, aunque tiene una amplitud y complejidad que dificultan caracterizarla ${ }^{7}$, no cabe duda de que continúa la orientación político criminal que iniciaron las precedentes, señaladamente las Leyes Orgánicas 7, 11 y $15 / 2003^{8}$.

Para hacerse una idea cabal de lo que ésta orientación supone, debe tenerse presente que actualmente reforma significa expansión del Derecho penal en extensión y en intensidad: incremento de la intervención penal con flexibilización de las garantías ${ }^{9}$, en otras palabras, aumento del número de delitos ${ }^{10} \mathrm{y}$ ampliación del ámbito de lo punible de los ya existentes ${ }^{11}$, incre-

medio se produce una reforma cada nueve meses. Sin embargo, el legislador parece estar satisfecho de tan desaforada actividad, ya que dice en el Preámbulo de la LO 5/2010 que "La evolución social de un sistema democrático avanzado [...] determina que el ordenamiento jurídico esté sometido a un proceso constante de revisión". Punto de vista del que discrepa SILVA SÁNCHEZ, 2010, 1, cuando califica estas palabras del legislador de "loa al activismo legislativo" y de "implícita crítica a una estabilidad que hasta hace poco era considerada un valor de especial entidad en la legislación penal".

${ }^{5}$ La expresión es de SILVA SÁNCHEZ, 2010, 1. Utiliza casi la misma expresión DÍAZMAROTO, 2010, 19, que se refiere al "profundo calado de la reforma". Asimismo subrayan la importancia de la reforma GONZÂLEZ CUSSAC, 2010, 39; MESTRE DELGADO, 2010, 5; QUINTERO OLIVARES, 2010, 18.

${ }^{6}$ DÍAZ-MATORO Y VILLAREJO, 2010, 21, indica que son exactamente 161.

${ }^{7}$ SILVA SÁNCHEZ, 2010, 1; QUINTERO OLIVARES, 2010, 18.

${ }^{8}$ Pone de relieve esta continuidad MUÑOZ CONDE, 2010, 7.

${ }^{9}$ SILVA SÁNCHEZ, 2009, 15; 2010, 2.

${ }^{10}$ Según MESTRE DELGADO, 2010, 5, son diez los delitos nuevos que introduce la presente LO. Ciertamente es discutible el criterio conforme al cual se otorga esta calificación, pero pueden considerarse que son "delitos nuevos" los tipificados en los arts. 156 bis (tráfico ilegal de órganos humanos); 172.3 (acoso inmobiliario); 173.1.3 (acoso laboral); 177 bis (trata de seres humanos); 183 bis (ciber acoso o child grooming); 197 (acceso no autorizado a datos, programas,..., informáticos); 282 bis (estafa de inversiones); 286 bis (corrupción entre particulares y en el deporte); 570 bis, ter, quáter (organizaciones y grupos criminales); 616 ter, quáter (piratería); y se podrían añadir otros como 187.1 (solicitud, aceptación u obtención a cambio de retribución de servicios sexuales por menores de 13 años); 328.2, 3, 4 y 5 (delitos relacionados con la gestión de residuos tóxicos) y 400 bis (uso de documento auténtico por quien no está legitimado).

${ }^{11}$ Son muy numerosos los preceptos que en los que la LO 5/2010 amplía el ámbito de lo punible y/o crea tipos agravados, así, p. ej. y sin ánimo de ser exhaustivo, en los delitos sexuales los arts. 180.1.3. $, 181.2,181.4,187.2$ y 189.1.a; en los delitos patrimoniales y socioeconómicos los arts. 234, 235, 242.2, 248.2.c, 257.3 y 4, 264, 284 y 301.1; en los delitos sobre la ordenación del territorio los arts. 319.1 .2 y 320.1 y 2 ; en los delitos contra los recursos naturales y el medio ambiente los arts. 325 y 329.1 ; en los delitos relativos a la protección de la flora, fauna y animales domésticos los arts. 334.1, 336 y 337; en los delitos de riesgo catastrófico los arts. 343.1, 345 y 348; en los delitos de falsedades documentales los arts. 392.2 y 399.2; en los delitos contra la Administración pública los arts. 419 y ss., 436, 439 y 445; en los delitos contra la Administración de Justicia el art. 451.3. ${ }^{\circ}$. a; en los deli- 
mento del elenco de penas (y medidas de seguridad $)^{12}$, de las penas establecidas para los distintos delitos ${ }^{13} \mathrm{y}$ endurecimiento de las normas relativas a su ejecución ${ }^{14}$, y flexibilización de las garantías ${ }^{15}$. Además en la línea de expansión de la intervención penal debe destacarse en esta reforma, por su

tos relativos a la tenencia, tráfico y depósito de armas, municiones o explosivos los arts. 566 y 567; en los delitos de terrorismo los arts. 576.3 y 576 bis; y en los delitos contra la Comunidad internacional los arts. 607, 607 bis, 612, 613 y 614 .

${ }^{12}$ La LO 5/2010 incluye en el elenco de penas la privación de la patria potestad (art. 33, $39,46)$, modifica la pena de localización permanente de forma relevante (art. 37) e incluye una nueva medida de seguridad, la libertad vigilada (arts. 98 y 106).

${ }^{13}$ Es muy amplio el número de preceptos en los que la presente LO incrementa la pena asignada a distintos delitos. Así entre otros, en los delitos sexuales: arts. 178, 180.1, 183, 187.1, 188, 189 y 189 bis; de descubrimiento y revelación de secretos: art. 197.8; patrimoniales y socioeconómicos: arts. 245, 264 y 301; contra la Hacienda Pública y la Seguridad Social: arts. 305, 306, 307, 308 y 309; contra los derechos de los ciudadanos extranjeros: art. 318 bis. 2 y 3; sobre la ordenación del territorio: arts. 319.1, 2 y 3 y 320.1 y 2; contra los recursos naturales y el medio ambiente: arts. $325,328.1$ y 329.1 ; relativos a la protección de la flora, fauna y animales domésticos: arts. 333, 334, 336 y 339; de tráfico de drogas: art. 369 bis; contra la seguridad vial: art. 385 bis; contra la Administración pública: arts. 419 y ss., 428, 429, 439 y 445; contra la Comunidad Internacional: art. 616.

Además los arts. 192 y 579.3 establecen la medida de seguridad de libertad vigilada a imponer tras el cumplimiento de la pena correspondiente en los delitos sexuales y de terrorismo respectivamente.

Por el contrario, los preceptos en los que pueden verse de una u otra forma una atemperación de las penas son ciertamente muchos menos: arts. 250.1, 270. 1, II y 274.2, II (delitos patrimoniales y socioeconómicos); art. 325.2 (delitos contra los recursos naturales y el medio ambiente); art. 368 (delitos de tráfico de drogas); arts. 379.1 y 2, 384 y 385 ter (delitos contra la seguridad vial); y arts. 387 y 399 bis (falsedades).

${ }^{14} \mathrm{La}$ LO 5/2010 atempera el alcance del periodo de seguridad como norma general, pero lo endurece respecto de determinados delitos. En este sentido no puede decirse que endurece el sistema de ejecución de penas, pero mantiene el endurecimiento de las reformas precedentes, en especial las de la LO 7/2003, relativas a la clasificación o progresión al tercer grado penitenciario, a los límites de la prisión en los casos de concurso real de delitos y a la libertad condicional (sobre éstas reformas véase ACALE SÁNCHEZ, 2004, 1208 ss.).

${ }^{15}$ SILVA SÁNCHEZ, 2010, 2. Es un lugar común en la doctrina subrayar la limitación de la vigencia que entrañan las reformas, para distintos principios de anclaje constitucional, que fundamentan y, por tanto, limitan el poder sancionador del Estado, así entre otros DÍEZ RIPOLLÉS, 2005, 30; GONZALEZ CUSSAC, 2003, 22 ss.; MAQUEDA ABREU, 2003, 10 s.; SANZ MORÁN, 2004, 12. Véase el estudio de las reformas penales habidas hasta el año 2005, que hace MATA BARRANCO, 2007, 14 ss., desde la perspectiva de "los principios que deben definir toda intervención penal", en el que señala la quiebra que sufren el principio de legalidad, de intervención mínima, de ofensividad, de culpabilidad (en su vertiente de principio del hecho) y de proporcionalidad en sentido amplio (humanidad, igualdad y reinserción social). La reforma de la LO 5/2010 continúa, acentuando en algunos casos, la línea emprendida por la reformas de 2003, como indica MUÑOZ CONDE, 2010, $7 \mathrm{~s}$. 
relevancia, la introducción de un "sistema jurídico-sustantivo completo" de responsabilidad penal de las personas jurídicas ${ }^{16}$.

La doctrina ha subrayado que las sucesivas reformas han creado "otro Derecho penal" 17 , un "nuevo Derecho penal" 18 , es decir, distinto al del CP de 1995; que se ha producido "la cristalización de un nuevo modelo penal": el Derecho penal de la seguridad ${ }^{19}$. Un Derecho penal en el que se eleva la seguridad a objetivo político criminal ${ }^{20}$ y cuyas penas pretenden en mayor medida metas de prevención general positiva (respuesta a la alarma social) y negativa (intimidación) y de inocuización del delincuente que de reinserción social de este ${ }^{21}$; y que por ello, en ocasiones, se desliza del Derecho penal que establece la responsabilidad e impone la pena en atención a la gravedad

${ }^{16}$ La expresión es de SILVA SÁNCHEZ, 2010, 1.

La responsabilidad de las personas jurídicas alcanza a los delitos de tráfico ilegal de órganos humanos (art. 156 bis.3), de trata de seres humanos (art. 177 bis.7), relativos a la prostitución y corrupción de menores (189 bis), de descubrimiento y revelación de secretos (art 197.3, II), de estafa (art. 251 bis), de insolvencia punible (art. 261 bis), de daños (art. $264,4)$, relativos a la propiedad intelectual e industrial, al mercado y a los consumidores (art. 288, II), de blanqueo de capitales (art. 302, 2), contra la Hacienda Pública y la Seguridad Social (art. 310 bis), contra los derechos de los ciudadanos extranjeros (art. 318 bis.4, III); sobre la ordenación del territorio (art. 319,4), contra los recursos naturales y el medio ambiente (arts. 327 y 328.6 y 7), de riesgo catastrófico (arts. 343.3 y 348.3), relativos al tráfico de drogas (art. 369 bis, III), de falsificación de tarjetas de crédito y débito y de cheques de viaje (art. 399 bis), de cohecho (art. 427.2), de tráfico de influencias (art. 430), de corrupción en las transacciones internacionales (art. 445.2) y de financiación del terrorismo (art. 576 bis).

${ }^{17}$ ZÚNIIGA RODRÍGUEZ, 2004, 99, refiriéndose sobre todo a las habidas en el año 2003.

${ }^{18}$ LANDROVE DÍAZ, 2009, que titula así su monografía.

${ }^{19}$ DÍEZ RIPOLLÉS, 2005, 10. Emplean similar expresión, ACALE SÁNCHEZ, 2004, 1199, que recuerda que el Ministro de Justicia calificó el conjunto de reformas como las necesarias para convertir el Código penal en el Código penal de la seguridad; y LANDROVE DÍAZ, 2003, 1923 ss.

${ }^{20}$ Sobre los distintos significados del término seguridad y la necesidad de precisarlo debidamente con el fin de que pueda ofrecer resultados, véase PAREDES CASTAÑÓN, 2006, 127 ss.

${ }^{21}$ SILVA SÁNCHÉZ et al., 2003, 114. SILVA SÁNCHEZ, 2010, 2, indica que no está clara la teoría de la pena que subyace a la reforma y afirma que "los aspectos de prevención general positiva se integran sin solución de continuidad con perspectivas retribucionistas", mientras que la incidencia de la rehabilitación y reinserción social es secundaria.

Ponen de relieve que la idea de resocialización o reinserción pasa a segundo plano en las reformas de 2003 SANZ MORÁN, 2004, 15, que subraya la presencia de la prevención general negativa; GONZÁLEZ CUSSAC, 2003, 23 s., que pone el acento en la inocuización (mantener apartado al delincuente de la sociedad); MAQUEDA ABREU, 2003, 8, que subraya la prevención general positiva y la inocuización. En sentido similar respecto de las orientaciones político-criminales actuales que se reflejan en las reformas de 2003, DÍEZ RIPOLLÉS, 2004(a), 12 ss.; 2004(b), 20 ss.; y 2005, 27, en especial, respecto de la inocuización. 
del hecho y a la culpabilidad del autor, hacia un Derecho penal que establece la sanción en atención a la peligrosidad real o presunta del delincuente ${ }^{22}$. Un derecho penal, por tanto, más represivo ${ }^{23}$ y autoritario ${ }^{24}$.

Este cambio de paradigma se viene produciendo también en el resto de los países de nuestro entorno ${ }^{25}$. Así puede verse, en parte, en los movimientos político criminales que desde hace buen número de años están presentes en EEUU (tolerancia cero, three strikes, ventanas rotas ${ }^{26}$ ), en parte en la propuesta de elaborar un derecho penal del enemigo proveniente de Alemania ${ }^{27}$ y a él responden también no pocas de las reformas que se derivan de la pertenencia a la Unión Europea y, en menor medida, de compromisos internacionales, cuya finalidad es luchar contra el terrorismo, la delincuencia organizada, etc. ${ }^{28}$

${ }^{22}$ Así sucede con la delincuencia leve reiterada, con la delincuencia grave, en especial, la sexual y terrorista y con la delincuencia organizada, como se expone más adelante Véanse apartados 6, 7 y 8. Véase también SILVA SÁCHEZ et al., 2003, 118, 124 ss.

Conviene indicar que, como pone de relieve SILVA SÁNCHEZ, 2001, 707, "la absolutización de la seguridad como objetivo político criminal conduce a la reconstrucción de un Derecho penal de la peligrosidad". En el mismo sentido también DÍEZ RIPOLLÉS, 2005, 26 ss.

${ }^{23}$ ZUGALDÍA ESPINAR, 2004, 1130, afirma que las reformas del Código penal "manifiestan una evidente incontinencia represiva"

${ }^{24}$ MUÑOZ CONDE, 2010, 7. En el mismo sentido respecto de las reformas de 2003, LANDROVE DÍEZ, 2003, 1925 y 1926, y 2009, 27; y VIVES ANTÓN, 2008, 265, que apunta a la deriva autoritaria que se percibe en el Anteproyecto de 2008 ya el título de su trabajo “¿Estado democrático o estado autoritario?” y posteriormente en varias reflexiones de su texto (págs. $266 \mathrm{~s}$.).

${ }^{25}$ BRANDARIZ GARCÍA, 2004, 16; GONZÁLEZ CUSSAC, 2010, 44; MAQUEDA ABREU, 2003, 9 s.; SILVA SÁNCHEZ et al., 2003, 113; SILVA SÁNCHEZ, 2010, 1, 3.

${ }^{26}$ Véanse sobre estas orientaciones BRANDARIZ GARCÍA, 2004, 15 ss.; CASTIÑEIRA / RAGUÉS, 2004, 59 ss.; LANDROVE DÍAZ, 2009, 29 ss.

${ }^{27}$ La propuesta proviene del profesor G. JAKOBS. Puede verse JAKOBS, 2000, 4 ss., y 2003, 19 ss. La bibliografía sobre el tema, en su inmensa mayoría decididamente crítica, es prácticamente inabarcable, véase por todos CANCIO MELIÁ / GÓMEZ-JARA DÍEZ (Coords.), 2006. Una muy breve síntesis de las consecuencias de esta propuesta en el sistema penal puede verse en DÍEZ RIPOLLÉS, 2005, $23 \mathrm{~s}$.

${ }^{28}$ SILVA SÁNCHEZ, 2010, 2, llama la atención sobre que son objeto de armonización europea y, en menor medida, internacional, también "crímenes odiosos", campo abonado para contemplar al delincuente como "otro" (en el sentido de "no yo") y que por ello se produce en no pocas ocasiones un debilitamiento de las garantías, ya que se busca con frecuencia el "mínimo común denominador de las garantías" de los distintos países. En el mismo sentido DÍEZ RIPOLLÉS, 2005, 13.

Entre las reformas introducidas por la LO 5/2010, que responden a este campo de "crímenes odiosos", se cuentan los delitos relacionados con la explotación de menores y la pornografía infantil (arts. 183, 187, 188 y 189), la trata de seres humanos (art. 177 bis), el tráfico de drogas (arts. 368 ss.), la delincuencia organizada y transnacional (arts. 570 bis ss.), el terrorismo (576 bis),... Pero no debe perderse de vista que en ocasiones la LO va más allá de la propuesta europea o internacional. Así sucede, p. ej., en el delito de trata de seres 
Además debe tenerse presente que este cambio en el modelo del Derecho penal es impulsado por prácticamente todos los partidos políticos del arco parlamentario $^{29}$ y se suele afirmar que es solicitado por la opinión pública ${ }^{30}$.

\section{Factores para su aceptación}

\section{Ausencia de incremento de la criminalidad y su percepción}

La aceptación generalizada de este paradigma no tiene su origen, al menos en España, en la necesidad de tomar medidas más o menos drásticas contra una delincuencia en constante aumento o desbordante.

A pesar de las dificultades que plantea determinar la evolución de la delincuencia en España ${ }^{31}$, hay cierto acuerdo en afirmar que se produjo un incremento sostenido de los delitos en los años ochenta, que su número se mantuvo estable en la primera mitad de los noventa, repuntando de nuevo hasta mediados de los dos mil; durante este periodo las faltas, a diferencia de los delitos, han seguido un incremente constante; en cuanto a la estructura de la delincuencia, prácticamente el $70 \%$ de las infracciones son hurtos y robos y los delitos contra las personas que venían representando un $2 \%$ del total en el año 2000, han pasado a constituir casi un $6 \%$ tras la reforma que sufrieron los malos tratos en el año 2003, aun cuando no se ha producido un cambio significativo en el número de homicidios y lesiones ${ }^{32}$.

humanos (art. 177 bis) respecto de la DM 2002/629/JAI, de 19. 7.2002, y el Convenio 197 del Consejo de Europa sobre la lucha contra la trata de seres humanos (Varsovia 15.5.2005); en los delitos de agresión y abuso sexuales sobre menores de 13 años (art. 183) respecto de la DM 2004/68/JAI del Consejo, de 23. 12. 2003; en los delitos de organización y grupo criminales (arts. 570 bis y ss.) respecto de la DM 2008/841/JAI del Consejo, de 29.4.2008; en los delitos de terrorismo (art. 579.1) respecto de la DM 2008/919/JAI, de 28.11.2008.

${ }^{29}$ CANCIO MELIÁ, 2003, 71 s.; DÍEZ RIPOLLÉS, 2004-b, 11, 23; LANDROVE DÍAZ, 2009, 57 s.; MAQUEDA ABREU, 2003, 8, citando a SILVA SÁNCHEZ, que habla

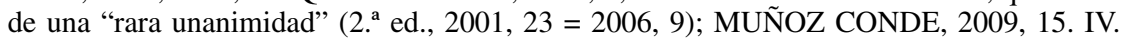
Consideraciones críticas

Cabe subrayar que el acuerdo entre los dos partidos mayoritarios permitió que la Comisión de Justicia del Senado dictaminara en tan sólo dos horas y media el Proyecto de reforma de la LO 5/2010, a pesar de se presentaban 280 enmiendas a su consideración; a su vez el Pleno del Senado lo aprobó en una sola sesión (véase ÁLVAREZ GARCÍA, 2010(b), 28).

${ }^{30}$ DÍEZ RIPOLLÉS, 2004(b), 26, indica que "la propia comunidad" se ha acabado por creer que la "receta" para hacer frente a la delincuencia está "compuesta sustancialmente de mano dura y de amplias dosis de incomprensión e incomunicación intersubjetivas" y critica su desinterés por las aportaciones de los expertos.

LARRAURI PIJOAN, 2009, 7, entiende, sin embargo, que la opinión pública española sea punitiva o, quizá mejor, punitivista (en el sentido de partidaria de incrementar la aplicación de la pena de prisión).

${ }^{31}$ Véase BRANDARIZ GARCÍA, 2007, 37; GARCÍA ESPAÑA et al., 2010, 2 ss.

${ }^{32}$ DÍEZ RIPOLLÉS, 2007, 9 ss. y 11 s., que tiene presente datos hasta el año 2004. 
Si atendemos a los estudios sobre la evolución de la delincuencia a través de encuestas de victimización, la conclusión es que la delincuencia desde 1980 hasta 2008 presenta una tendencia descendente, si bien se hace patente un ligero incremento de delitos entre 2005 y 2008, siendo los hurtos y los robos en viviendas los delitos que más han aumentado ${ }^{33}$.

El Informe semestral del Gabinete de Estudios de Seguridad Interior sobre la evolución de la criminalidad en los últimos 12 meses (junio 2010) en el ámbito de actuación del Cuerpo Nacional de Policía y de la Guardia Civil, indica que la tasa anual de criminalidad -número de delitos y faltas por 1.000 habitantes- ha descendido desde el año $2000(45,9)$ a junio de 2010 $(45,1)$ tras haber alcanzado el máximo el $2002(52,1)^{34}$ y permite apreciar un descenso en los homicidios y asesinatos dolosos (de 3,09 a 2,35) ${ }^{35}$, aunque aumenta la tasa del conjunto de los delitos contra la vida, integridad y libertad de las personas (de 1,61 a 2,68) ${ }^{36}$ probablemente por la reforma sufrida en materia de malos tratos en el ámbito familiar ${ }^{37}$; asimismo puede apreciarse un importante descenso en la tasa de los delitos patrimoniales (de 20,1 a $15,2)^{38}$; por su parte, las faltas de lesiones mantienen una tasa similar (de 2,06 a 2,05) y las faltas de hurto ascienden ligeramente (de 11,4 a 12,7) ${ }^{39}$.

Cabe destacar, por tanto, cualquiera que sea la fuente que se tome en consideración, que a diferencia de lo que sucedió en los años ochenta, el incremento de las infracciones a partir de los años noventa hasta hoy está lejos de alcanzar tasas preocupantes, es más, presenta conforme a los estudios citados un ligero descenso a finales de esta década o, cuando menos, "mantiene una clara tendencia a la estabilidad" 40.

Cuestión distinta es cómo perciben la criminalidad los ciudadanos. Conforme a la citada encuesta de victimización el $88,8 \%$ de los encuestados consideraba que la delincuencia ha aumentado mucho o bastante en los últimos

${ }^{33}$ GARCÍA ESPAÑA et al., 2010, 9 ss., 18 ss., 22 s., 24. Estos mismos autores indican que las conclusiones que ofrecen las estadísticas oficiales discrepan: presentan un incremento constante de la delincuencia desde 1980, pero también ponen de relieve que se produjo un estancamiento en la segunda mitad de los noventa y un decrecimiento en el periodo de 2004 a 2008. Esta discrepancia podría deberse en parte al ascenso de la tasa de denuncias y, por consiguiente, de conocimiento de los delitos por parte de los órganos del Estado.

${ }^{34}$ GABINETE DE ESTUDIOS DE SEGURIDAD INTERIOR, 2010, 3.

${ }^{35}$ GABINETE DE ESTUDIOS DE SEGURIDAD INTERIOR, 2010, 11.

${ }^{36}$ GABINETE DE ESTUDIOS DE SEGURIDAD INTERIOR, 2010, 8.

${ }^{37}$ Puede observarse que se pasa de 1,76 en el año 2003 a 2,30 en el 2004, es decir, tras la reforma.

${ }^{38}$ GABINETE DE ESTUDIOS DE SEGURIDAD INTERIOR, 2010, 14, descenso que es común a todos delitos que se especifican (robo con violencia, "tirones" en la vía pública, robo con fuerza en viviendas, que repunta, sin embargo, en 2008 y hasta el presente aunque en tasas muy inferiores a las de 2002, y sustracción de vehículos).

${ }^{39}$ GABINETE DE ESTUDIOS DE SEGURIDAD INTERIOR, 2010, 21.

${ }^{40}$ BRANDARIZ GARCÍA, 2007, 37. 
años, pudiéndose concluir del estudio que los ciudadanos están más convencidos del incremento de la criminalidad y tienen un mayor miedo al delito, cuanto más información sobre hechos delictivos reciben, siendo determinante para ello la frecuencia y la forma en que esta realidad sea tratada por los medios de comunicación ${ }^{41}$.

\section{Cambio en la valoración de la criminalidad}

El cambio de paradigma que sufre el Derecho penal, no responde, por tanto, a la necesidad de tomar medidas drásticas contra una delincuencia que aumenta de forma preocupante ${ }^{42}$. Más bien es fruto de la percepción que se tiene de ella y de la valoración de que es objeto, en último término, de un cambio ideológico al respecto, que ha dado lugar a que la ideología de la seguridad se haya adueñado del panorama político criminal.

En este sentido cabe indicar que se ha producido un cambio importante a la hora de aproximarse a la explicación de la delincuencia y, en consecuencia, a los objetivos que corresponden al Derecho penal. Se dejan de lado las explicaciones sociales (estructurales) que toman en consideración situaciones de desigualdad de distinta índole y que en alguna medida responsabilizan a la sociedad de la misma y se avienen con la resocialización como función de la pena. Actualmente se acude a explicaciones que ponen el acento en la decisión personal del delincuente de aprovechar las ventajas que le reporta el delito; perspectiva voluntarista, que engarza con la idea de hacer más duras las sanciones para combatir la delincuencia y con el uso más intenso de la prisión. Desde este planteamiento se entiende que los costes de la prevención del delito deben quedar a cargo del delincuente y no de la sociedad, de forma que se abandona la resocialización como función de la pena y se contempla la inocuización selectiva, buscando por medio del encarcelamiento y control neutralizar el riesgo de reincidencia ${ }^{43}$. En la misma línea de pensamiento se mueve la tendencia a excluir de la sociedad a quienes de forma grave o reiterada infringen las normas penales y denotan su disposición a seguir delinquiendo (terrorismo, delincuencia organizada, delincuencia sexual, económica, violenta, habitual y profesional), llegándo-

${ }^{41}$ GARCÍA ESPAÑA et al., 2010, 22 s., 24. Véase en sentido semejante BOTELLA / PERES-NETO, 2008, 43 ss.; BAUCELLS / PERES-NETO, 2008, 109 ss.; FUENTES OSORIO, 2005, 3 s.; y SOTO NAVARRO, 2005, 41 ss.

42 Taxativo al respecto VIVES ANTÓN, 2008, 266, recordando que el Anteproyecto de 2008 se anunció el mismo día que el Delegado del Gobierno para la Comunidad Valenciana anunciaba que la delincuencia había descendido con respecto al año anterior. A la misma conclusión llevan los datos que aportan y el discurso que realizan BRANDARIZ GARCÍA, 2007, 37 ss.; DÍEZ RIPOLLÉS, 2007, 9 ss., 129 ss.; LARRAURI PIJOAN, 2009, 4 s.; MAQUEDA ABREU, 2003, 8.

${ }^{43}$ Véase DÍEZ RIPOLLES, 2005, 17 ss. 
se incluso a negar su condición de ciudadanos y proponiéndose para ellos un derecho penal distinto al aplicable a la generalidad de quienes infringen la ley: el derecho penal del enemigo, que no respondería los mismos principios $^{44}$.

Otro cambio relevante afecta al papel que se atribuye y ocupan las víctimas del delito, cuyas demandas se encuentran en el centro de los debates político-criminales actuales. La mayoría social se identifica con las víctimas, ya que se ven como víctimas potenciales, de forma que sus demandas encuentran la solidaridad de la sociedad. El clamor por el respeto a sus intereses y sentimientos dificulta que se tenga presente el complejo equilibrio que debe mantenerse en el sistema penal entre los legítimos intereses públicos y de la víctima, por una parte, y los legítimos intereses del procesado, por otra. Camino por el que se llega a considerar como un escarnio para las víctimas determinadas garantías del proceso o el disfrute por el condenado de determinadas situaciones del sistema de ejecución de las penas ${ }^{45}$.

Es un lugar común en la doctrina hacer referencia al sentimiento social de inseguridad que caracteriza la sociedad actual, como caldo de cultivo idóneo para el nacimiento y arraigo del Derecho penal de la seguridad. Desde hace años se viene calificando la sociedad en que vivimos como "sociedad del riesgo" 46 , a la vista de los nuevos peligros que surgen en muy distintos ámbitos a causa de la aplicación intensiva de distintas técnicas y de las nuevas tecnologías (energía atómica, industria química, explotaciones petrolíferas, farmacología, biotecnología,...); peligros que nacen en ocasiones de su falta de conocimiento, de uso inadecuado o de su concurrencia con otras fuentes de peligro, que podría no ser prevista e, incluso, imprevisible, de forma que se hace casi imposible no ya su control sino determinar quién es responsable del mismo ${ }^{47}$. Pero junto a la inseguridad derivada de estos riesgos, que ha dado lugar a una notable expansión del Derecho penal ${ }^{48}$, pero no a un

${ }^{44}$ JAKOBS, 2003, 21 ss., que indica como principios diferenciales el adelantamiento de "la penalidad un gran techo hacia el ámbito de la preparación" y la dirección de la pena "hacia el aseguramiento frente a hechos futuros, no a la sanción de los hechos cometidos" (p. 40) y, por último, en el Derecho procesal la limitación o supresión de ciertas garantías (p. 43 ss.).

${ }^{45}$ Véanse las exposiciones de DÍEZ RIPOLLÉS, 2004, 9 ss.; y SILVA SÁNCHEZ, 2006, 46 ss. Muy ilustrativa GARCIA ARÁN /PERES-NETO, 2008, 153 ss., 188.

${ }^{46}$ Es indiscutible la influencia de la obra de Ulrich BECK, La sociedad del riesgo. Hacia una nueva modernidad (Ed. Paidós. Barcelona. 1998), de cuyo título procede la expresión y cuya edición alemán se remonta a 1986.

${ }^{47}$ MENDOZA BUERGO, 2003, 67 ss.; SILVA SÁNCHEZ, 2006, 13 ss.

${ }^{48}$ Sobre esta expansión del Derecho penal -que según algunos corresponde a su "modernización"- se ha producido una viva polémica doctrinal, de la que realiza un acertado resumen DÍEZ RIPOLLÉS, 2005, 3 ss., con amplias referencias.

Son cuatro los rasgos que definen la política criminal que pretende dar respuesta a la sociedad del riesgo, según expone DÍEZ RIPOLLÉS, 2005, 4 s.: $1 .^{\circ}$ ampliación de los ámbi- 
Derecho penal de la seguridad ${ }^{49}$, se encuentran otros, que son causantes de una inseguridad más sentida. Los ciudadanos tienen dificultades para afrontar una vida social que evoluciona de forma cada vez más rápida, que es cada vez más abierta culturalmente $-\mathrm{y}$, por tanto, con valores y referencias menos seguros-, más tecnológica, más competitiva, más individualista; una sociedad que cada vez es menos controlable, en la que cada vez es más fácil quedar excluido; una sociedad, en una palabra, menos segura para los ciudada$\operatorname{nos}^{50}$. Ausencia de seguridad que incrementa el paulatino desmantelamiento, anunciado y/o efectivo, del estado del bienestar, consecuencia directa o menos de la crisis económica, cuyos efectos son paro, precariedad en el empleo, limitación de derechos laborales y de seguridad social, dificultades crecientes en el acceso a una sanidad, educación o vivienda,... de calidad, que afectan perjudicialmente a las condiciones de vida presentes y a las expectativas de futuro de importantes capas sociales ${ }^{51}$.

En este contexto nada tiene de extraño que arraigue la percepción de la delincuencia como un peligro, como una amenaza, y que el sentimiento colectivo de inseguridad ciudadana ocupe un lugar destacado, aunque sea más bien "una liviana cortina, que vela un conjunto de malestares, que se han asentado firmemente entre la población en los últimos años" 52 , "una expre-

tos sociales de intervención del derecho penal (fabricación y distribución de productos, medio ambiente, sectores tecnológicos, orden socioeconómico,...); $2 .^{\circ}$ transformación del centro de atención de la nueva política criminal: la criminalidad de los poderosos; $3 .^{\circ}$ preeminencia del instrumento penal en detrimento de otros instrumentos de control social para la prevención de tales conductas ; $4 .^{\circ}$. Necesidad de acomodar el Derecho penal y procesal a las dificultades de persecución de la nueva criminalidad. A su vez, las siguientes notas caracterizan al Derecho penal resultante de tal política criminal: 1. ${ }^{\mathrm{a}}$ incremento de la criminalización de conductas consecuencia del reconocimiento de bienes jurídicos de carácter colectivo; 2 . $^{\text {a }}$ predominio de las estructuras típicas de simple actividad, ligadas a delitos de peligro o de lesión ideal del bien jurídico; 3 a $^{\mathrm{a}}$ anticipación del momento en que procede la intervención penal; 4 . $^{a}$ modificaciones en el sistema de imputación de responsabilidad y en el conjunto de garantías penales y procesales.

${ }^{49}$ Acertadamente diferencia DÍEZ RIPOLLÉS, 2005, 5 ss., la política criminal securitaria y el Derecho penal de la seguridad ("seguridad ciudadana") de la política criminal y Derecho penal de la sociedad del riesgo (de la "modernización") -cuyos planteamientos y consecuencias son distintos, aunque en ocasiones se superpongan-, criticando la confusión entre ambas orientaciones político criminales y, concretamente, el planteamiento de SILVA SÁNCHEZ, 2006, 13 ss. Véase asimismo DÍEZ RIPOLLES, 2004(b), 7, n. 7. Ya con anterioridad, como pone de relieve asimismo DÍEZ RIPOLLÉS, 2005, 11, n. 22, MENDOZA BUERGO, 2003, 72, n. 16, y PAREDES CASTAÑóN, 2003, 91 s., 111, habían diferenciado los riesgos propios de la sociedad del riesgo (riesgos técnicos / seguridad técnica) y otros riesgos a los que responde la seguridad pública o interior.

${ }^{50}$ SILVA SÁNCHEZ, 2006, 18 ss.; DÍEZ RIPOLLÉS, 2005, 28 s. MAQUEDA, 2003, 7.

${ }^{51}$ BRANDARIZ GARCÍA, 2004, 39 SS.; DÍEZ RIPOLLÉS, 2004(b), 28: MAQUEDA ABREU, 2003, 6 s.; SILVA SÁNCHEZ, 2006, 18.

${ }^{52}$ DÍEZ RIPOLLÉS, 2004(b), 28. "El miedo al delito -dice SILVA SÁNCHEZ, 2006, 30- aparece como una metáfora de la inseguridad vital generalizada". 
sión simbólica de esos sentimientos de temor"53, que una buena parte de la doctrina atribuye, al menos en parte, a la "labor interesada de unos medios de comunicación de comunicación empeñados en servir de apoyo a una política estatal igualmente interesada en administrar la «seguridad interna»"

Ciertamente los medios de comunicación informan una y otra vez de delitos de muy distinta índole (terrorismo, homicidios, robos violentos, violencia de género, agresiones sexuales, reiteración de delitos de poca gravedad sobre todo contra la propiedad,...) con un alto grado de dramatización y de forma que parece que se está produciendo un incremento insoportable de la delincuencia, que impide una vida social medianamente pacífica. Al tiempo no son pocas las ocasiones en que tales informaciones van acompañadas de críticas acervas a la lenidad del sistema penal como causa de tal situación. Por ello se exige del Estado seguridad, es decir, que tome las medidas que sean necesarias con el fin de frenar la delincuencia, de neutralizar esa fuente de peligros. En esta línea se solicita una intervención penal más intensa, que pasa frecuentemente por una disminución de garantías (mayor facilidad para aplicar la prisión preventiva, introducción de la prisión perpetua, endurecimiento en la ejecución de las penas,... $)^{55}$. La adopción de estas medidas está dirigida más que a producir efectos reales en la contención de la delincuencia -es opinión mayoritaria que el endurecimiento de las penas carecen de eficacia disuasoria ${ }^{56}$-, a producir reacciones sociales inmediatas de carácter estabilizador e integrador, que refuerzan la confianza institucional y demuestran solidaridad a las víctimas, a "los nuestros" (prevención general positiva de integración) y, al mismo tiempo, apartan socialmente al delincuente, al "otro" (prevención especial negativa de inocuización) $)^{57}$. Reacciones que resultan políticamente rentables -prácticamente sin coste económico alguno- y que no producen los enfoques estructurales de la delincuencia, más eficaces en el largo plazo, pero que colocan al poder ejecutivo y legislativo en dificultades, ya que evidencian la presencia de unas causas que no han corregido, así como la complejidad y el coste de las medidas a adoptar ${ }^{58}$.

${ }^{53}$ MAQUEDA ABREU,2003, 7, citando a BECK.

${ }^{54}$ MAQUEDA ABREU, 2003, 7, quien se remite a BECK,1998, 248, para indicar que es de las escasas competencias que todavía conserva el Estado. BOTELLA CORRAL / PERES-NETO, 2008, 64 s.; DİEZ RIPOLLÉS, 2004(b), 25; LANDROVE DÍAZ, 2003, 1925 , que indica que los medios actúan "de forma no siempre inocente".

${ }^{55}$ Véanse BOTELLA CORRAL / PERES-NETO, 2008, 43 ss.; FUENTES OSORIO, 2005, 1 ss.; GARCÍA ARÁN / PERES-NETO, 2008, 153 ss.

${ }^{56}$ MAQUEDA ABREU, 2003, 11, con referencias; MUÑOZ CONDE, 2010, 7; PAREDES CASTAÑÓN, 2006, 148; SILVA SÁNCHEZ, 2009, 16, con referencias de la doctrina alemana y más detenidamente 2010, 3 s., asimismo con referencias; VIVES ANTÓN, 2008, 272.

${ }^{57}$ MAQUEDA ABREU, 2005, 8; PÉREZ CEPEDA, 2007, 86 s.

${ }^{58}$ DÍEZ RIPOLLÉS, 2004(b), 29 ss. 
Nada tiene de extraño, pues, que las reivindicaciones sociales de seguridad se acaben plasmando en reformas, que reflejan esta orientación político criminal que defiende una importante intensificación de la intervención penal, con el fin de remediar la insuficiencia de los mecanismos clásicos frente al peligro de delincuencia, con el fin de producir en los ciudadanos seguridad, confianza ${ }^{59}$.

\section{Manifestaciones en la reforma penal de 2010 (LO 5/2010)}

Todas las reformas que sufre el CP por la LO 5/2010 no responden a la progresiva presencia en él del Derecho penal de la seguridad ${ }^{60}$. Algunas tienen carácter técnico ${ }^{61}$, otras son fruto de la política criminal que surge con la sociedad del riesgo o, si se quiere, de la llamada "modernización" del Derecho penal ${ }^{62}$ y no faltan las que responden, como dice el Preámbulo de la LO, al "surgimiento de nuevas cuestiones que han de ser abordadas"63. Pero son abundantes las reformas que introducen rasgos que de una $\mathrm{u}$ otra forma revelan que el Código penal responde en mayor medida que con anterioridad a ese nuevo modelo de Derecho penal securitario. Baste pensar en el incremento de la pena prevista para buen número de delitos o en la creación de tipos agravados ${ }^{64}$, con la consecuencia de asegurar o facilitar que se cumpla la pena de prisión en un amplio número de delitos ${ }^{65}$. En estos casos la pena no parece que esté dirigida a la reinserción, sino más bien a la intimidación y a la inocuización del autor así como a producir un efecto de prevención

\footnotetext{
${ }^{59}$ Véase GARCÍA ARÁN / PERES-NETO, 2008, 153 ss.

${ }^{60}$ QUINTERO OLIVARES, 2010, 18, subraya que "resulta imposible exponer un hilo conductor común".

${ }^{61}$ Se pueden calificar de tales, entre otras, la regulación de la atenuante de dilaciones indebidas (art. 21, 6. ${ }^{\mathrm{a}}$ ), la regulación del abono de la prisión preventiva (art. 58. 2, 3 y 4), las reglas para el cómputo de la prescripción (art 132), la ampliación del concepto de llave falsa (art. 239, II), la tipificación expresa de la estafa procesal (art. 250.1.7. ${ }^{\circ}$ ).

${ }^{62}$ Puede decirse que responden a esta orientación (véanse n. 49 y 50) la introducción de la responsabilidad de las personas jurídicas (véase nota 17), la introducción de la estafa de inversiones (art. 282 bis), las alteraciones de precios, manipulación del mercado y uso de información privilegiada (art. 284) o la corrupción entre particulares (art. 286 bis).

${ }^{63}$ Por esta vía algunos autores hacen referencia a temas que califican de "coyunturales", aunque no es claro si entienden lo mismo por tales. Así QUINTERO OLIVARES, 2010,17, se refiere a la libertad vigilada, que a su juicio alcanza relevancia debido la puesta en libertad tras el cumplimiento de la pena de algunos delincuentes sexuales, que son considerados peligrosos, y SILVA SÁNCHEZ, 2010, 1 s., se refiere, por su parte, al tratamiento de la comisión reiterada de faltas de hurto (art. 623.1) o al de los hechos de bagatela en materia de propiedad industrial e intelectual (top manta, art. 623.5).

${ }^{64}$ Véase nota 14.

${ }^{65}$ En este sentido SILVA SÁNCHEZ. 2010, 4, respecto de los delitos de los arts. 305, 307 y 325.1 y lo mismo puede decirse de los delitos sexuales -a los que se hará referencia más detenida en el siguiente apartado- arts. 178, 187 y189.
} 
general positiva, cual es el de comunicar que se trata de delitos cuya pena es efectivamente privativa de libertad, saciando -al igual que en el resto de los supuestos de incremento de penal- sentimientos sociales de carácter vindicativo $^{66}$. De todos modos son tres los campos en que hace más patente la intensificación de la intervención penal en clave securitaria: la delincuencia leve reiterada de carácter patrimonial, la delincuencia individual grave violenta, especialmente, los delitos sexuales y terroristas; y, por último, la criminalidad organizada, especialmente, en el marco del terrorismo ${ }^{67}$.

\section{Delincuencia leve reiterada de carácter patrimonial}

La reiteración en el delito es contemplada por el CP como agravante de reincidencia, cuando media condena previa por un delito del mismo título (art. 22, 8. ${ }^{\mathrm{a}}$ ), de forma que se impone la pena en su mitad superior (art. 66. 1. 3. ${ }^{\mathrm{a}}$ ). La LO 15/2003 incluyó además la posibilidad de imponer la pena superior en grado en los casos de tres condenas previas (multirreincidencia, art. 66. 1. 5. ${ }^{\text {a }}$. La reincidencia implica asimismo la imposibilidad de que sea suspendida la ejecución de la pena ordinaria (art. 81.1..$^{\mathrm{a}}$ ) y puede impedir la suspensión especial de la ejecución de la pena prevista para drogodependientes (art. 87.2).

También es reconocida la reiteración como habitualidad -comisión de tres o más delitos de los comprendidos en el mismo capítulo en un plazo no superior a cinco años, mediando condena por ellos (art. 94, I ${ }^{68}$-, aunque con efectos más limitados. Impide la sustitución extraordinaria de penas de prisión de hasta 2 años (art. 88.1).

La LO 15/2003 otorgó además nuevos efectos a la reiteración. La comisión de cuatro faltas de lesiones, hurto y hurto o robo con fuerza en las cosas de vehículos a motor en el período de un año, da lugar a que se consideren constitutivas respectivamente de un delito de lesiones, de hurto o de hurto o robo con fuerza de uso de vehículo a motor (arts. 147, 234,

\footnotetext{
${ }^{66}$ SILVA SÁNCHEZ, 2010, 4, que entiende que en estos casos no se trata de lograr un efecto de intimidación o disuasión genera ni a la resocialización, sino de intimidación individual e inocuización, pero tal vez la efectiva presencia de la prisión tenga también efectos de prevención general negativa, p. ej., en delitos como los del 305, 307 y 325.1.

${ }^{67}$ DÍEZ RIPOLLÉS, 2005, 15, n. 38, destaca que es mérito de SILVA SÁNCHEZ et al., 2003,113 , haber puesto de relieve que en estos grupos de delitos se ha producido una intensificación de la intervención penal a pesar de que se trata de delitos propios del derecho penal tradicional, es decir, distintos a los propios del Derecho penal fruto de la "modernización" derivada de la sociedad del riesgo (véanse notas 49 y 50).

${ }^{68} \mathrm{El}$ art. 94 indica expresamente que caracteriza la habitualidad de esta forma a efectos de la sección 2. ${ }^{a}$ del capítulo, esto es, a efectos de la sustitución de las penas privativas de libertad.
} 
$244)^{69}$. Ahora la LO 5/2010 endurece esta norma respecto del hurto, reduciendo a tres las faltas de hurto que es preciso realizar para que esta reiteración se considere constitutiva de delito (art. 234).

Por último, la reforma de 2010 tiene presente la reiteración en la falta de hurto, de modo que en estos casos la pena será necesariamente la de localización permanente de cuatro a doce días y "el Juez podrá disponer en sentencia [...] que se cumpla en sábados, domingos y días festivos en el centro penitenciario más próximo al domicilio del penado" (arts. 632.1 y 37.1) ${ }^{70}$.

Puede observarse, por tanto, que la reforma de 2010 profundiza la línea seguida por la de 2003, cuyo objeto fue permitir y/o reforzar la aplicación de la pena de prisión, de la privación de libertad, en estos $\operatorname{casos}^{71}$.

Se hace necesario resaltar que resulta muy difícil justificar el incremento de pena introducido para la reiteración delictiva por las reformas. La doctrina mayoritaria considera que ni la mayor gravedad (antijuridicidad) del hecho ni la mayor culpabilidad del autor constituyen fundamento convincente para la agravación de la pena por reincidencia -y menos aún para la agravación excepcional por multirreincidencia-, cuya constitucionalidad además ha sido puesta en tela de juicio ${ }^{72}$; y tampoco encuentra aceptación por las

${ }^{69}$ Por este camino se hace posible la aplicación de penas de prisión a estos delitos constituidos por una reiteración de faltas, porque las penas que les corresponden son respectivamente para las lesiones prisión de seis meses a tres años (art. 147.1); para el hurto prisión de seis a dieciocho meses (art. 234); para el hurto de uso de vehículos a motor trabajos en beneficio de la comunidad de 31 a 90 días o multa de seis a doce meses en caso de que lo restituyere directa o indirectamente, y si no hubiere restitución, prisión de seis a dieciocho meses (art. 244.1 y 3); y éstas últimas penas en su mitad superior para el robo de uso con fuerza en las cosas (art. 244.2 y 3 ).

${ }^{70}$ Curiosamente en la nueva regulación que recibe la pena de localización permanente resurge en parte la pena de arresto de fin de semana que había desaparecido con la reforma de 2003. En este sentido TORRES ROSELL, 2010, 93, poniendo de relieve que el Preámbulo indica que con ella se pretende incrementar el arsenal de penas alternativas, cuando en realidad se posibilita por esta vía la entrada en prisión del condenado y se trata de producir "cortas, pero efectivas descargas punitivas”. En sentido próximo GONZÁLEZ TASCÓN, 2010, 96, entiende que se renuncia "a salvaguardar al condenado del efecto criminógeno" en aras de la prevención general negativa y de que "en el condenado se intensifique su efecto shock".

${ }^{71}$ Recuerda LANDROVE DIÁZ, 2003, 1924, que desde determinadas opciones políticas se habló de limpiar las calles, de que debe acabarse con el espectáculo de que los delincuentes entren por una puerta y salgan por la otra de los establecimientos penitenciarios. Por su parte DÍEZ RIPOLLÉS, 2005, 29, recuerda la frase "barrer la delincuencia de las calles". Expresiones que revelan la voluntad de que se facilite o asegure la prisión como respuesta a determinados comportamientos.

${ }^{72}$ Sobre el fundamento de la reincidencia véase por todos en relación con la reforma de 2003, JIMÉNEZ DÍAZ, 2006, 44 ss., que expone las distintas posturas doctrinales sobre su fundamento y el cuestionamiento de su constitucionalidad -que resolvió la STC 150/1991, de 4 de julio, a favor de su constitucionalidad- y hace patente el rechazo de la doctrina mayoritaria a mantenerla como agravante, en buena medida, por colisionar con el principio de culpabilidad. 
mismas razones la construcción de distintos delitos a partir de la reiteración de faltas de lesiones, hurto, etc. ${ }^{73}$. En realidad se trata de supuestos que guardan relación con la peligrosidad del autor, es decir, con la probabilidad de que el sujeto vuelva a delinquir; peligrosidad, que además se presume en la medida en que no es preciso comprobarla para imponer la sanción y que, en su caso, debiera ser neutralizada con la correspondiente medida de seguri$\mathrm{dad}^{74}$. Se produce, pues, un deslizamiento hacia un derecho penal de peligrosidad, de autor, en el que la responsabilidad se establece en mayor medida en atención a la peligrosidad de éste que a su responsabilidad ${ }^{75}$.

En segundo lugar, hay que poner de relieve que la pena está dirigida a escarmentar a estas personas por medio de la prisión y sobre todo a excluirles de la vida social por un tiempo ${ }^{76}$. El objeto de la estancia en prisión que estas normas pretenden permitir o asegurar, ciertamente no puede verse en la reinserción, dada su breve duración y la desocialización que produce la prisión. Se trata, por tanto, de una pena dirigida a intimidar al sujeto y a inocuizar su peligrosidad -curiosamente no comprobada-, que tiene el efecto de facilitar o, en su caso, reforzar la marginación ${ }^{77}$. En todo caso, esta forma de intervención penal no tiene presente ni trata de incidir en las causas de la delincuencia sino en sus síntomas ${ }^{78}$.

\section{Delincuencia grave violenta, en especial, delitos sexuales y de terrorismo}

La delincuencia grave, en especial, los delitos sexuales violentos y los de terrorismo, conmociona de forma especial el sentimiento social de seguridad ante el temor de que el hecho se repita en el futuro. No puede pasarse por alto además, que se atribuye a estos delincuentes caracteres personales en virtud de los cuales la pena no tiene capacidad de intimidatoria ni resocializadora, de forma que su cumplimiento no permite excluir el riesgo que representan. De ahí que se solicite la neutralización de la fuente de peligro, la inocuización del delincuente por medio de medidas asegurativas como la prisión perpetua o medidas de seguridad ulteriores al cumplimiento de la pena ${ }^{79}$.

${ }^{73}$ Véase asimismo JIMÉNEZ DÍAZ, 2006, 85 ss. y 115 ss., con referencias.

${ }^{74}$ SILVA SÁNCHEZ et al., 2003, 118.

${ }^{75}$ DÍEZ RIPOLLÉS, 2005, 26, pone de relieve que la primacía que se otorga en el discurso de la seguridad a la peligrosidad del delincuente y planteamientos como la gestión administrativa o actuarial de los riesgos tienen como consecuencia el resurgimiento del derecho de la peligrosidad, que presta atención especial a los creadores de inseguridad y entre ellos a los reincidentes y habituales, entre los que destaca los autores de la delincuencia patrimonial leve reiterada.

${ }^{76}$ SILVA SÁNCHEZ et al., 120. En el mismo sentido DÍEZ RIPOLLÉS, 2005, $17 \mathrm{~s}$.

${ }^{77}$ DÍEZ RIPOLLÉS, 2005, 28; MAQUEDA ABREU, 2003, 11, desde una perspectiva más amplia que abarca también a los extranjeros.

${ }^{78}$ DIEZ RIPOLLÉS, 2005, 16 ss.; JIMÉNEZ DÍAZ, 2006, 84 y 141.

${ }^{79}$ SILVA SÁNCHEZ et al., 2003, $121 \mathrm{~s}$. 
Esta tendencia a introducir medidas inocuizadoras se manifiesta en las reformas, que han afectado no sólo al Código penal, sino también a la Ley de Enjuiciamiento Criminal.

La prisión provisional es, sin duda, una las medidas que cumple esta función, al menos, tras las reformas de que fue objeto su art. $503 \mathrm{LECr}$ por las LO 13 y 15/2003, que admiten la posibilidad de acordar, cumpliéndose determinados requisitos, la prisión provisional con el fin de que el imputado no pueda actuar contra bienes jurídicos de la víctima o cometer otros delitos. Es la peligrosidad del autor, la que determina la adopción de esta medida privativa de libertad, que desde un punto de vista material se conforma en estos casos como una medida de seguridad predelictual. Y lo mismo puede decirse de medidas cautelares civiles y penales (prohibición de aproximarse a la víctima y un largo etc.) que se han introducido especialmente por la LO $1 / 2004^{80}$.

También son significativas en este sentido las modificaciones que se han introducido en el CP. En el marco de los delitos sexuales se crea un delito nuevo ${ }^{81}$, se amplía la tipicidad de algunas figuras y se crean tipos agrava$\operatorname{dos}^{82}$ y se incrementan las penas establecidas para distintos delitos ${ }^{83}$. Además la LO 7/2003 endureció de forma muy significativa el acceso al tercer grado penitenciario (régimen abierto) al exigir que se haya cumplido la mitad de la pena, cuando ésta tenga una duración superior a los cinco años, pudiendo el Juez de Vigilancia Penitenciaria, en su caso, acortar este periodo, siempre que no se trate de delitos de terrorismo y de los cometidos en el seno de organizaciones criminales (art. 36) ${ }^{84}$. La reforma de 2010 vuelve a modificar estas normas. Por una parte, las atempera al invertir la regla, de forma que el Juez o Tribunal podrá ordenar que la clasificación en tercer grado penitenciario no se efectúe hasta que se haya cumplido la mitad de la pena, pero en principio no juega esta limitación; por otra, las agrava al aumentar el número de delitos en los que se limita la posibilidad de acceder al tercer grado antes del cumplimiento de la mitad de la pena, con los abusos y agresiones sexuales a menores de trece años y los delitos relativos a la prostitución y corrupción de menores, cuando la víctima fuera menor de 13 años $\left(\right.$ art. 36) ${ }^{85}$.

De nuevo puede verse que se contempla más al autor de estos delitos por el peligro que encierra -a un autor tipo al que puede no responder quien efec-

${ }^{80}$ DÍEZ RIPOLLÉS, 2005, 27; SILVA SÁNCHEZ et al., 2003, 120 y 124.

${ }^{81}$ Art. 183 bis que tipifica el denominado ciber acoso o child grooming.

${ }^{82}$ Arts. 180.1.3. ${ }^{\circ}, 181.2,181.4,182,183,187.1,187.2,188,189.1$.

${ }^{83}$ Arts. 178, 180.1, 183, 187.1, 188 y 189.

${ }^{84}$ Véase ACALE SÁNCHEZ, 2004, 1197 ss., en especial, 1208 ss.

${ }^{85}$ Véanse BACH FABREGÓ / GIMENO CUPERO, 2010, 84 ss.; GONZÁLEZ TASCÓN, 2010, 91 ss. 
tivamente comete el delito ${ }^{86}$, que a consideraciones de otra índole. Podríamos preguntarnos por qué no se toman idénticas medidas respecto otros delitos tan graves como éstos, como el asesinato por precio o el secuestro con fines lucrativos.

La reforma de 2010 no varía el límite máximo de cumplimiento de las penas de prisión en los casos de pluralidad de delitos, a los que se aplicarán las normas del concurso, de forma que pueden prolongarse hasta los 40 años cuando el sujeto haya sido condenado por dos o más delitos y al menos dos de ellos estén castigados por ley con una pena superior a los 20 años y también cuando el sujeto haya sido condenado por dos o más delitos de terrorismo y alguno de ellos esté sancionado con pena superior a 20 años (art. 76, reformado por la LO 7/2003). Tampoco varía el endurecimiento de los requisitos de acceso a los beneficios penitenciarios, permisos de salida, tercer grado y libertad condicional en aquellos casos en que por aplicación de las normas relativas a los concursos, la pena a cumplir resulta inferior a la mitad de la suma de las penas correspondientes a los delitos, de forma que el Juez o Tribunal sentenciador podrá acordar que se apliquen a la totalidad de las penas impuestas en las sentencia (art. 78, reformado por la LO 7/2003). Por último, mantiene asimismo la mayor rigidez para acceder a la libertad condicional para terroristas o delincuencia organizada, a los que se exige para que se considere que hay un pronóstico favorable de reinserción social, que el penado haya colaborado activamente con las autoridades para impedir la producción de otros delitos por parte de la banda armada, para atenuar los efectos de su delito o para la identificación, captura y procesamiento de responsables de delitos terroristas, lo que podrá acreditarse mediante la declaración expresa de repudio de las actividades y de abandono de la violencia y una petición expresa de perdón a las víctimas así como por los informes técnicos que acrediten que el preso está realmente desvinculado de la organización (art. 90, reformado por LO 7/2003) ${ }^{87}$.

Estas normas tienen presente la clase de autor -según los casos, delincuente sexual, terrorista o quien comete el delito en el seno de una organización criminal- y que lo relevante es proceder a su inocuización. Pues bien, la reforma de 2010 da un paso más en esta orientación con la introducción de la libertad vigilada, medida de seguridad no privativa de libertad de hasta cinco años, salvo cuando expresamente se disponga que sea de hasta 10 años. La libertad vigilada trata de hacer frente a los supuestos en que el cumplimiento de la pena no ha eliminado la peligrosidad del penado ${ }^{88}$, sometiéndole en caso de que se considere necesario a un control judicial mediante el

${ }^{86}$ Debe notarse además que en los delitos indicados el Juez de Vigilancia Penitenciaria no puede decidir la aplicación del régimen general de cumplimiento por disposición del propio art. 36.2. III.

${ }^{87}$ Véase ACALE SÁNCHEZ, 2004, 1216 ss., 1221 ss.

${ }^{88}$ Véase el Preámbulo de la LO 2/2010. 
cumplimiento de una o varias medidas (hasta 11) que van de la obligación de estar localizable a seguir un determinado tratamiento médico, pasando por la prohibición de residir o de acudir a determinados lugares o de ausentarse ${ }^{89}$. Esta medida de seguridad solamente está prevista para los delitos de terrorismo (art. 579.3) y sexuales (art. 192).

Una vez más se hace patente el mismo planteamiento: neutralizar la posible peligrosidad de un determinado tipo de autores: delincuentes sexuales y terroristas, que se aviene con su concepción de personas en las que no incide la pena ni en su función de intimidación ni en la de reinserción. Se recurre por ello a la inocuización por medio de la duración y el régimen de ejecución de las penas de prisión, a la que además se le añade para su cumplimiento posterior una medida de seguridad de libertad vigilada de hasta 10 años. Por este camino tal vez se neutralice la peligrosidad del delincuente y sobre todo se logren los efectos psico-sociales, que se pretenden: crear confianza institucional satisfaciendo anhelos sociales de castigo por tan graves delitos, pero salen mal parados no pocos principios de rango constitucional, comenzando por los de proporcionalidad y culpabilidad, que abarca el principio del hecho y de reinserción. mientras se mantenga la regulación actual ${ }^{90}$.

\section{Criminalidad organizada, especialmente, en el marco del terrorismo}

Criminalidad organizada, especialmente, en el marco del terrorismo. La denominada delincuencia organizada se presenta como una de las mayores fuentes de inseguridad por su potencialidad delictiva ${ }^{91}$. En este sentido el Preámbulo de la LO 5/2010 afirma:

${ }^{89}$ Véanse ACALE SÁNCHEZ, 2010, 148 ss.

${ }^{90}$ En caso de que resulte necesaria una intervención tras el cumplimiento de la pena por la peligrosidad del sujeto, habrá de establecerse correctamente la proporcionalidad de tal medida basándose en el criterio de distribución de riesgos entre individuo y sociedad, como indica DÍEZ RIPOLLÉS, 2005, 28, citando a SILVA SÂNCHEZ, 2001, 709 s., de forma que la medida se levante cuando corresponda soportar le riesgo a la sociedad. Lo que no resulta aceptable es determinar la duración de la pena, su forma de ejecución o la imposición de una medida de seguridad a cumplir con posterioridad al cumplimiento de la pena en atención a la clase de delito cometido que se manifiesta como indicio de peligrosidad.

${ }^{91}$ SILVA SÁNCHEZ et al., 2003, 128, ponen en duda si realmente existen "necesidades objetivas de protección" frente a esta delincuencia o si nos encontramos ante una "demanda social desmesurada e irracional de punición", concluyendo que constituye "un problema nuevo en expansión" a causa de factores como la mundialización de la economía o la aparición de nuevas zonas sumidas en la anomia (implosión del bloque soviético), pero que también "es objeto de una intensa instrumentalización".

De interés GIMÉNEZ-SALINAS FRAMIS et al., 2009, 1 ss., en especial, 25 s., que concluyen la existencia de una mayor de detección de la delincuencia organizada en España desde 1998 gracias al esfuerzo policial, pero que a la vista de las dificultades de medición, "quedaría por contrastar si ese aumento representa una realidad o simplemente un aumento de la presión policial. 
"dichas organizaciones, aparte de multiplicar cuantitativamente la potencialidad lesiva de las distintas conductas delictivas llevadas a cabo en su seno o a través de ellas, se caracterizan en el aspecto cualitativo por generar procedimientos e instrumentos complejos específicamente dirigidos a asegurar la impunidad de sus actividades y de sus miembros, y a la ocultación de sus recursos y de los rendimientos de aquéllas, en lo posible dentro de una falsa apariencia de conformidad con la ley, alterando a tal fin el normal funcionamiento de los mercados y de las instituciones, corrompiendo la naturaleza de los negocios jurídicos, e incluso afectando a la gestión y a la capacidad de acción de los órganos del Estado".

No obstante, la amplitud con que se tipifican los delitos relativos a esta materia no parece que respondan a una decisión político-criminal con raíces en una peligrosidad similar a la expuesta, que justifique en todo caso adelantar la intervención penal a momentos anteriores a la efectiva realización de delitos, además, con unas penas tan graves ${ }^{92}$.

El texto legal diferencia entre organizaciones y grupos criminales. Las primeras requieren la agrupación de dos o más personas con carácter estable que de manera concertada y coordinada se repartan diversas tareas y funciones, con el fin de cometer delitos o llevar a cabo faltas de forma reiterada. Se sanciona promover, constituir, coordinar o dirigir una organizaciones criminal y con una pena inferior también la pertenencia y la colaboración a las mismas. En unos y otros casos la gravedad de la pena difiere según la gravedad de la finalidad perseguida por la organización: la comisión de delitos graves o de delitos leves y faltas. Como agravantes se toman en consideración distintas circunstancias que les dotan de mayor peligrosidad (elevado número de personas, tenencia de armas, disposición de medios tecnológicos avanzados), pudiéndose imponer la pena superior en grado cuando concurran varias de ellas. En todos los casos se imponen las penas correspondientes en su mitad superior, si los delitos a cometer fueren contra la vida o la integridad de las personas, la libertad, la libertad e indemnidad sexuales o la trata de seres humanos (art. 570 bis).

Los grupos criminales, en cambio, son formas de concertación criminal que no encajan en las organizaciones, pero otorgan un plus de peligrosidad a las acciones de sus componentes. El texto legal los define como la unión de

${ }^{92}$ Con anterioridad a la reforma de la LO 5/2010 en distintos delitos se tipificaba como agravante, aplicable por tanto tan sólo a los que intervinieren en el delito, la pertenencia a una asociación incluso transitoria; así en los arts. 187, 262, 271, 276, 318 bis o 386). A partir de la entrada en vigor de la reforma incurrirán en responsabilidad criminal a título de organización o grupo criminal también quienes todavía no hayan realizado acto de ejecución alguno de los delitos o faltas reiteradas que la organización o el grupo tenga por fin cometer. 
dos o más personas, que no reúne alguna de las características de las organizaciones criminales y tiene por finalidad la comisión concertada de delitos así como la perpetración reiterada de faltas. Se sanciona constituir, financiar o integrar tales grupos y las penas difieren según cuál sea el delito o delitos propuestos, distinguiendo hasta siete modalidades. Asimismo se prevé la agravación de las penas en los mismos casos que para las organizaciones criminales (art. 570 ter) ${ }^{93}$.

El hecho de que las organizaciones y grupos criminales puedan quedar constituidas por la agrupación de más de dos personas, es decir, tres o cuatro, hace que pueda quedar de hecho excluida la diferencia entre criminalidad profesional y criminalidad organizada, lo que privaría de legitimación a la drástica intervención penal que supone la presencia de una organización de una complejidad mucho mayor ${ }^{94}$.

Además las dificultades que ha venido planteando en la práctica la prueba de los elementos propios de las organizaciones, tienen como consecuencia que el legislador cree otra figura de rango inferior: el grupo, de modo que es suficiente con que medie un acuerdo estable para cometer delitos o de forma reiterada faltas ${ }^{95}$. Pero con este recurso se difumina la diferencia entre la criminalidad organizada y la conspiración para realización de varios delitos por una pluralidad de personas que actúa de mutuo acuerdo (p. ej., cuatro individuos que se conciertan para sustraer un vehículo que facilite su huída tras cometer el atraco que han decidido cometer, o acuerdan sustraer varios cheques en blanco con el fin de cumplimentarlos y presentarlos al cobro en una entidad bancaria), de forma que el modelo a que responde se aleja de forma muy notable del peligro potencial que supone la criminalidad organizada y, por tanto, decae el fundamento y, en consecuencia, la justificación de la sanción ${ }^{96}$. Por ello se ha apuntado que esta figura delictiva, grupo crimi-

\footnotetext{
${ }^{93}$ Véanse GARCÍA RIVAS / LAMARCA PÉREZ, 2010, 505 ss.; MARTELL PÉREZALCALDE / QUINTERO GARCÍA, 2010, 358 ss.

${ }^{94}$ SILVA SÁNCHEZ, et al., 2003, $130 \mathrm{~s}$.

95 En este sentido indican MARTELL PÉREZ-ALCALDE / QUINTERO GARCÍA, 2010,364, que "el grupo criminal se comporta como concepto residual o de recogida respecto de la organización delictiva".

${ }^{96}$ MARTELL PÉREZ-ALCALDE / QUINTERO GARCÍA, 2010, 364 s., entienden que si faltan las notas de la organización (la estabilidad o el reparto de funciones) la respuesta penal vendrá dada por la tipicidad y la coautoría u otras formas de participación, si se han llevado a cabo actos de ejecución y si no, por la conspiración. conspiración o la coautor; por este camino, indican, se llega a sancionar en todos los delitos e, incluso, en la realización de faltas de forma reiterada la conspiración, contra la decisión del CP de 1995 de que salvo excepciones fuera impune; por ello apuntan que puede que el texto legal, aunque no lo diga expresamente esté pensando en la profesionalidad, como nota que podría caracterizar el grupo. Por su parte GARCÍA RIVAS / LAMARCA PÉREZ, 2010, 510 s., ponen de relieve la dificultad, pero recurren al tradicional concepto de banda o "cuadrilla" del CP 1973 y lo diferencian de la conspiración, en que en ésta existe ya la determinación de realizar un con-
} 
nal, se ha creado para los casos en que no sea posible probar la existencia de una organización criminal, de modo que se asemeja peligrosamente a un delito de sospecha (no se ha logrado probar, pero se sospecha la existencia) de organización criminal ${ }^{97}$.

Por último, llama la atención que se incluya dentro de las organizaciones y grupos criminales, los que tienen por objeto la comisión reiterada de faltas, ya que excede la obligaciones de la Decisión Marco 2008/841/JAI, de $24.10^{98}$. Ciertamente estos supuestos carecen de la peligrosidad que se predica de las organizaciones criminales y no es fácil justificar la pena de uno a tres años prisión o de tres meses a un año, que como mínimo se les atribuye en los arts. 570 bis. 1 y 570 ter, 1 , aun cuando todavía no haya realizado ni siquiera un acto ejecutivo de alguna de las faltas. La tipificación de estas conductas y las penas que se les atribuyen, son una medida adicional contra la delincuencia leve reiterada ${ }^{99}$, que responde a las mismas pautas que las vistas en el apartado correspondiente, relacionadas en buena medida con la peligrosidad de los autores.

Por último, no puede pasarse por alto que las organizaciones y grupos criminales en sí mismos representan un peligro para los bienes jurídicos de los delitos y faltas que tienen por objeto cometer, pero la imposición de la pena a quien pertenece o colabora con la organización entraña en cierta forma una transferencia de responsabilidad de la organización o grupo al miembro o colaborador. A este se le castigará por los hechos delictivos que realice y además por su pertenencia o colaboración con la organización o grupo y esta segunda sanción se corresponde realmente con la peligrosidad que representa su adhesión o aportación a la organización o grupo, de forma que se produce una vez más un deslizamiento hacia el derecho penal de autor ${ }^{100}$.

creto delito, mientras que en el grupo el concierto no está vinculado a la comisión de un concreto delito. Punto de vista que debe complementarse, porque tiene que existir acuerdo en la clase de infracciones a cometer con el fin que pueda ser tipificado el hecho conforme al 570 ter.

${ }^{97}$ SILVA SÁNCHEZ et al., 2003, 131, indicando que por medio de este delito no se trata tanto de describir la conducta para imponerle una pena, cuanto de establecer el medio para tomar una serie de medidas cautelares que permitan la investigación, etc.

MARTELL PÉREZ-ALCALDE / QUINTERO GARCÍA, 2010, 360 s., ponen de relieve que los instrumentos internacionales relativos a esta materia (Decisión del Consejo de la UE 2004/579/CE, de 29. 4, que aprueba la Convención de la ONU para la lucha contra la delincuencia organizada transnacional de 15.11 .2000 y la DM 2008/841/JAI, de 24.10) no exigen que se tipifique como delito el grupo criminal.

${ }^{98}$ MARTELL PÉREZ-ALCALDE / QUINTERO GARCÍA, 2010, 361.

${ }^{99}$ En este sentido MARTELL PÉREZ-ALCALDE / QUINTERO GARCÍA, 2010, 361, consideran que se trata una medida contra una criminalidad específica que azota el turismo en las grandes ciudades.

100 SILVA SÁNCHEZ et al., 2003, 132 s. 
Puede verse, por tanto, una intervención penal desmedida, ya que no queda suficientemente justificada y se aleja claramente de los principios de proporcionalidad y de culpabilidad, en su vertiente de responsabilidad por el hecho, lo que lo aproxima al derecho penal de autor ${ }^{101}$.

También en el ámbito del terrorismo se tipifican expresamente las organizaciones y grupos terroristas, que se definen con los mismos elementos que acabamos de ver en los arts. 570 bis y 570 ter, si bien requieren la finalidad de subvertir el orden constitucional o alterar gravemente la paz pública mediante la perpetración de los delitos previstos entre los de terrorismo (art. 571.3), que prevé para estos delitos penas que pueden llegar hasta los 14 y 12 años de prisión respectivamente, además de las correspondientes de inhabilitación de hasta 15 y 14 años (art. 571.1 y 2).

La respuesta de que es objeto la criminalidad organizada, especialmente, la terrorista está dirigida a inocuizar la peligrosidad de tales delincuentes: adelantamiento de las barreras de protección a la pertenencia o colaboración con organizaciones o grupos criminales, incremento de las penas de prisión, endurecimiento de su de ejecución de forma que se dificulte o impida el acceso a determinados grados (tercer grado, libertad condicional) o a beneficios que reduzcan la duración de la pena, acumulación y cumplimiento sucesivo de pena y medida de seguridad en los casos de terrorismo ${ }^{102}$. Endurecimiento de la respuesta, al que se añaden, en el caso del terrorismo, distintas medidas en el orden procesal penal ${ }^{103}$. En su conjunto todas estas medidas representan un derecho penal distinto en sus principios al llamado a aplicarse al "delincuente normal", pudiéndose calificar de respuesta propia del derecho penal del enemigo ${ }^{104}$, que el propio JAKOBS caracteriza como "un no-derecho, una pura reacción defensiva de hecho frente a sujetos excluidos" $"$.

\section{Consideraciones críticas}

Son varias las críticas que merece el conjunto de medidas propias del Derecho penal de la seguridad que han ido introduciendo las reformas del CP.

Puede decirse, en primer lugar, que responden a un modelo que carece de memoria histórica y por ello anticuado. Suponen un paso atrás, el retorno a la prisión como casi única solución, cuando hace prácticamente un siglo

${ }^{101}$ SILVA SÁNCHEZ et al., 2003, 133.

${ }^{102}$ Véanse el apartado anterior en relación con los arts. 36.2, 76, 78, 90, 91 y 579.3 CP.

${ }^{103}$ Véase la referencia del apartado anterior a la prisión preventiva (art. $502 \mathrm{ss}$. LECr.) y nótese que el art. 520 bis LECr establece limitaciones al derecho de defensa.

104 Sobre la "infiltración" del discurso del derecho penal del enemigo en los delitos de terrorismo véase ASUA BATARRITA, 2006, 255 ss.

${ }^{105}$ La expresión es de JAKOBS, 2000, 31. 
que existe un amplio acuerdo en la doctrina sobre la necesaria humanización de las penas de prisión: las penas privativas de libertad de corta duración son injustas e ineficaces por tener efectos socialmente excluyentes y por ello deben ser sustituidas por penas alternativas a la prisión; y las penas de prisión de larga duración deben ser individualizadas en su ejecución, de forma que permitan la progresión de grado (de más riguroso a libertad condicional) bajo el control judicial con el fin de que faciliten la resocialización de los penados ${ }^{106}$. Las reformas, por tanto, profundizan en la tradicional deficiencia del sistema penal español de penas alternativas, muy alejado de los parámetros europeos, que tan sólo limitadamente pretendía superar el CP de $1995^{107}$; trastocan el sistema de ejecución de las penas privativas de libertad de larga duración relegando el objetivo constitucional de reinserción en favor de la inocuización ${ }^{108}$; y olvidan toda aproximación a la justicia restaurativa (procesos de mediación y reparación) que ofrece asimismo un interesante protagonismo a la víctima ${ }^{109}$.

En segundo lugar, hay que tener presente que los efectos de la previsión indiscriminada de la prisión da lugar a que nos encontremos ante un sistema excesivamente represivo $\mathrm{y}$, por tanto, poco justificable. La tasa de criminalidad española es menor que la media de los países europeos. El año 2009 la tasa española de delitos por 1000 habitantes fue de 45,8, mientras que la media europea -UE (15)- fue de 67,8, superando este límite Suecia (121), Bélgica (96), Dinamarca (88,4), Reino Unido (84,7), Holanda (74,5), Alemania $(73,9)$, Luxemburgo $(71,2)$ y Austria $(71,1)^{110}$. Sin embargo España tiene el índice de presos más alto de Europa por cada 100.000 habitantes: 157. Las cárceles cerraron diciembre de 2009 con 76.079 internos. En los últimos 9 años no ha dejado de aumentar el número de reclusos (31.462, un 70\%), indicándose por la Secretaría General de Instituciones Penitenciarias que tal incremento es fruto de los sucesivas reformas legales ${ }^{111}$. Además es previsi-

${ }^{106}$ MAQUEDA ABREU, 2003, 9; DÍEZ RIPOLLÉS, 2007, 53, de quien son respectivamente las expresiones en negrita.

${ }^{107}$ DÍEZ RIPOLLÉS, 2007, 54.

${ }^{108}$ MAQUEDA ABREU, 2003, 9.

${ }^{109}$ GRUPO "Otro derecho penal es posible", 2010, 7. Debe notarse además que la voluntad del legislador de cumplir las obligaciones derivadas de la pertenencia a la Unión Europea, no ha alcanzado al cumplimiento de la Decisión Marco 2001/220/JAI del Consejo de 15 de marzo de 2000, referida a esta materia.

${ }^{110}$ GABINETE DE ESTUDIOS DE SEGURIDAD INTERIOR, 2010, 3, 5, donde se indica que las tasas de los países europeos corresponden a los años 2008 o 2009 según la disponibilidad de datos. Por delante de España se encuentran también Irlanda $(67,5)$, Finlandia $(65,7)$, Italia $(57)$ y Francia $(45,1)$ y solamente Grecia $(38,2)$ y Portugal $(37,7)$ por detrás.

${ }^{111}$ Véase GRUPO "Otro derecho penal es posible", 2010, 1.

Sobre el incremento de reclusos en el periodo de 1996 - 2006 apuntando remedios al mismo, véase CID MOLINÉ, 2008 (n. ${ }^{\circ}$ 6, artículo 2), 2 ss., en especial, 23 ss., que coincide en parte con la afirmación de la Secretaría General de Instituciones Penitenciarias. 
ble que de la mano de la presente reforma siga creciendo el número de reclusos y sigamos con ese primer puesto europeo que choca con el índice de criminalidad. La cuestión en este momento es, por tanto, ¿de dónde nace una tal necesidad de encarcelar, que sitúa a España muy por encima de la ratio europea y a los centros penitenciarios en una situación de hacinamiento tal que convierte en quimera la posibilidad de reinserción y, lo que es más grave, el mandato constitucional de que la pena de prisión no prive al recluso de más derechos que los vinculados a la condena (art. 25.2) $)^{112}$.

En tercer lugar, cabe afirmar taxativamente que se trata de una reforma con ribetes autoritarios y socialmente excluyente. La intervención penal atiende a la peligrosidad del sujeto, a la que se combate con medidas que no toman en consideración su integración social, sino que con el fin de neutralizarla, recurre a la exclusión de la sociedad: la prisión. El coste de la prevención corre únicamente a cargo de quien delinquió y no de la sociedad, lo que supone para la delincuencia común reiterada de escasa gravedad, propia de colectivos marginales (pobres, gitanos, extranjeros, drogadictos,...), una nueva dificultad para su integración social ${ }^{113}$.

En cuarto lugar, es un modelo peligroso desde el punto de vista democrático, que está produciendo un "elevadísimo coste para el sistema de garantías"114 y "efectos devastadores en la estructura de racionalidad del derecho penal" 115 . Pone el acento en las características del autor: delincuente habitual, peligroso, colectivo, al que se sanciona no por lo que ha hecho o, al menos no sólo por lo que ha hecho, sino por lo que puede hacer. Se desliza hacia un derecho penal de autor tan en boga durante el periodo del fascismo y sobre todo del nacionalsocialismo, y de nefasta memoria. ;Otra vez falta de memoria histórica! Si lo relevante es neutralizar la peligrosidad del autor, ¿dónde se encuentran los límites de la intervención penal?, ¿en la exigencia de seguridad de la sociedad?, ¿cuáles son los límites de las intervenciones?, ¿puede llegarse dado el caso a la medidas pre-delictivas? Y si nos preguntamos por los límites nos estamos preguntando por la legitimidad de la intervención punitiva del estado. Lo cierto es que este modelo renuncia

112 DÍEZ RIPOLLÉS, 2007, 55, quien indica que también rigor punitivo del sistema español se hace presente en el tiempo de estancia media en prisión de los reclusos españoles que prácticamente doblaba en 2003 a la media de los países del Consejo de Europa y nada hace pensar que estos datos hayan tenido que variar a la vista de las reformas que ha sufrido el CP.

113 DÍEZ RIPOLLÉS, 2005, 29; en el mismo sentido MAQUEDA ABREU, 2003, 11. Entre el 70 y el $80 \%$ de los reclusos en centros penitenciarios pertenece a estos colectivos como recuerdan DÍEZ RIPOLLÉS, 2007, 53, y MAQUEDA ABREU, 2003, 11, citando a SILVA SÁNCHEZ, 2001, 57 (= 2007, 53). De extraordinario interés para conocer el perfil de los reclusos (“¿Quiénes son?”) GALLEGO DÍAZ et al., 2010, 61 ss.

${ }^{114}$ MAQUEDA ABREU, 2003, 10.

${ }^{115}$ DÍUEZ RIPOLLÉS, 2005, 30, con referencias. 
paulatinamente a distintos principios garantistas -"referencias claves en la racionalidad ética arraigada en nuestro sistema de creencias"116-. La responsabilidad no se establece ya en virtud de la gravedad del hecho y la culpabilidad del autor, que nos proponen una cierta proporcionalidad de la pena. La inocuización de la peligrosidad nos puede llevar a su total distorsión. ¿Es admisible una condena a 50 años de prisión por dos hurtos intentados, como ha admitido el Tribunal Supremo de EEUU? ${ }^{117}$ El principio de proporcionalidad, pero también el de legalidad, el de mínima intervención, el de ofensividad, el de humanidad de las penas, el de resocialización, el del hecho y el de igualdad se debilitan ${ }^{118}$.

En quinto lugar, no se puede perder de vista que el incremento de las penas con el fin de combatir la delincuencia es un modelo que no ha llegado a mostrar su eficacia. Es opinión mayoritaria en la doctrina, avalada por buen número de estudios, que el incremento de las sanciones no disminuye la delincuencia ${ }^{119}$. En relación con la delincuencia leve reiterada ciertamente EEUU donde más se ha aplicado este modelo, no ofrece datos que lo avalen: se trata de políticas criminales que resultan eficaces en el corto plazo, pero que no tienen resultados sostenidos en el tiempo ${ }^{120}$. No parece que pueda ser de otra forma, ya que es un modelo desenfocado, que combate los síntomas de la delincuencia sin ocuparse de las causas, sobre las que también es necesario actuar, eludiendo soluciones simplistas ${ }^{121}$. Como indica DÍEZ RIPOLLÉS, descuida las causas sociales de la delincuencia y "pone de forma poco realista las esperanzas en los efectos del aislamiento social de colectivos cada vez más amplios" ${ }^{122}$.

Es, por último, un derecho penal que revela una legitimación insuficiente en el marco de un estado social y democrático de derecho. El estado no puede recurrir a cualquier medio con el fin de mantener una convivencia pacífica que se ve amenazada por la delincuencia. Su objetivo ha de ser el de contener la delincuencia con el menor coste posible en los bienes jurídicos de quienes infringen la ley, que son en todo caso ciudadanos, no enemigos. Este límite en absoluto se cumple en este modelo de derecho penal: es notablemente más represivo que el de otros países de nuestro entorno, a pesar de nuestra menor tasa de delitos; no ha llegado a mostrar su eficacia y exige la renuncia a una parte importante del sistema de garantías. Ciertamente no

116 DÍEZ RIPOLLÉS, 2005, 30.

117 Véase CASTIÑEIRA / RAGUÉS, 2004, 63, 79.

118 Véase MATA BARRANCO, 2007, 14 ss.

${ }^{119}$ Véanse referencias en la nota 57.

${ }^{120}$ DÍEZ RIPOLLÉS, 2005, 29.

${ }^{121}$ ASUA BATARRITA, 2006, 245 s., citando a DÍEZ RIPOLLÉS, 2005, 10-16, 28 ss.; SILVA SÁNCHEZ et al., 2003, 115.

122 DÍEZ RIPOLLÉS. 2005, 30. 
puede llegarse a legitimar en atención a los efectos de integración social de este tipo de normas penales, que tratan de galvanizar a la mayoría social en torno a determinados valores; en ningún caso esto tipo de efectos de orden político pueden quedar legitimados a la vista del coste que tienen; ¿cómo la lesión excesiva, innecesaria - al menos comparativamente con otros paísesde bienes fundamentales de ciudadanos, cuya preservación constituye un objetivo prioritario de Estado, puede legitimarse para lograr objetivos políticos de esa índole?

\section{Consideración final}

Todo ello cuestiona seriamente la política criminal securitaria de la reforma de 2010 (LO 5/2010) y exige elaborar una política criminal distinta. Como bases para ella pueden tomarse las pautas que por contraste se derivan de las deficiencias que hemos puesto de relieve en las críticas hechas a lo largo de este trabajo. Debiera ser fruto de una discusión abierta, basada en datos reales; alejada de informaciones manipuladoras de sentimientos colectivos y de todo intento de obtener ventaja política de la inseguridad y del miedo; de una complejidad que necesariamente rebasa los slogans y otros recursos populistas y requiere una presencia decisiva de peritos en la materia; ajena a concepciones ingenuas y/o simplificadoras de la delincuencia, que tome en consideración la responsabilidad de los infractores así como la influencia de las estructuras sociales, de la desigualdad de oportunidades en la criminalidad; atenta a las muy diversas realidades que manifiestan conductas tan dispares como las que se agrupan bajo el término delincuencia o criminalidad y que por ello están necesitadas de respuestas asimismo diferenciadas y no sólo de orden punitivo; que atienda a una racionalidad orientada tanto a los fines de seguridad ciudadana como a los valores de un estado social y democrático de derecho. Tan sólo a partir de bases de esta índole puede llegarse a una política criminal de corte firmemente democrático por eficaz en la lucha con la delincuencia y por respetuosa con las garantías.

\section{BIBLIOGRAFÍA}

ACALE SÁNCHEZ, María: "Del Código penal de la democracia al Código penal de la seguridad”, en PÉREZ ÂLVAREZ, Fernando (Ed.), Serta. In memoriam Alexandri Baratta, CISE / Ed. U. Salamanca, Salamanca, 2004, págs. 1197 - 1226.

ACALE SÁNCHEZ, María: "Libertad vigilada", en ÁLVAREZ GARCÍA, Francisco Javier/ GONZÁLEZ CUSSAC, José Luis (Dirs.): Comentarios a la reforma penal de 2010. Tirant lo Blanch, Valencia, 2010, págs. $147-158$. 
ÁLVAREZ GARCÍA, Francisco Javier/ GONZÁLEZ CUSSAC, José Luis (Dirs.):"¿Otra reforma más?”, en ÁLVAREZ GARCÍA, Francisco Javier/ GONZÁLEZ CUSSAC, José Luis (Dirs.): Consideraciones a propósito del Proyecto de Ley de 2009 de modificación del Código Penal. Tirant lo Blanch, Valencia, 2010, págs. 11 - 17.

ÁLVAREZ GARCÍA, Francisco Javier: "Código penal y política criminal", en ÁLVAREZ GARCÍA, Francisco Javier/ GONZÁLEZ CUSSAC, José Luis (Dirs.): Comentarios a la reforma penal de 2010. Tirant lo Blanch, Valencia, 2010, págs. $17-38$.

ASÚA BATARRITA, Adela: "El discurso del enemigo y su infiltración en el Derecho penal, Delitos de terrorismo, "finalidades terroristas, y conductas periféricas", en CANCIO MELIÁ, Manuel/ GÓMEZ-JARA DÍEZ, Carlos (Coords.): El Derecho penal del enemigo. El discurso de la exclusión. Edisofer. Madrid / Ed. BdF. Buenos Aires. 2006, págs. 239 - 276.

BACH FABREGÓ, Roser / GIMENO CUBERO, Miguel Ángel: "Clases y contenido de penas y ejecución de las penas (arts. 33, 36, 39, 46, 50, 52, 53, 56, 58, 66 bis, 83, 100, 103, y 116 CP”, en QUINTERO OLIVARES, G., La Reforma Penal de 2010: Análisis y Comentarios. Aranzadi / Thomson Reuters, Cizur Menor,2010, págs. 71 - 90.

BAUCELLS I LLADÓS, Joan/ PERES-NETO, Luiz: "Discurso televisivo sobre le crimen: los programas especializados en sucesos", en GARCÍA ARÁN, Mercedes/ BOTELLA CORRAL, Joan (Dirs.), Malas noticias. Medios de comunicación, política criminal y garantías penales en Espa$\tilde{n} a$. Tirant lo Blanch, Valencia, 2008, págs. $109-151$.

BOCOS REDONDO, Pedro: "Entrada en vigor de la Ley de Contratos del Sector Público. Cómputo de plazos y vacatio legis", en El Consultor de los Ayuntamientos y de los Juzgados, 2008, págs. 1346 - 1349.

BOTELLA CORRAL, Joan/ PERES-NETO, Luiz: "La formación de la opinión pública y la construcción de discursos sobre la realidad criminal en España”, en GARCÍA ARÁN, Mercedes/ BOTELLA CORRAL, Joan (Dirs.), Malas noticias. Medios de comunicación, política criminal y garantías penales en España. Tirant lo Blanch, Valencia, 2008, págs. 43 $-65$.

BRANDARIZ GARCÍA, José Ángel: "Itinerarios de la evolución del sistema penal como mecanismo de control social en las sociedades contemporáneas", en BRANDARIZ GARCÍA, José Ángel, Nuevos retos del Derecho penal en la era de la globalización, Tirant lo Blanch, Valencia, 2004, págs. $15-63$.

BRANDARIZ GARCÍA, José Ángel: "Seguridade ciudadá, sociedade do risco e retos inabordables da política criminal", en Revista Galega de Seguridade Pública, 2007 (n. . 9), págs. 35 - 54.

CANCIO MELIÁ, Manuel: “¿Derecho penal del enemigo?, en JAKOBS, Günther - CANCIO MELIÁ, Manuel: Derecho penal del enemigo. Thomson-Civitas. Madrid, 2003, págs. 57 - 102. 
CANCIO MELIÁ, Manuel/ GÓMEZ-JARA DÍEZ, Carlos (Coords.): El Derecho penal del enemigo. El discurso de la exclusión. Edisofer. Madrid / Ed. BdF. Buenos Aires. 2006.

CASTIÑEIRA, Teresa/ RAGUÉS, Ramón: “Three strikes. El principio de proporcionalidad en la jurisprudencia del Tribunal Supremo de los Estados Unidos", en Revista de Derecho penal y Criminología, n. ${ }^{\circ}$ 14, 2004, pp. $59-85$.

CID MOLINÉ, José: "El incremento de la población reclusa en España entre 1996-2006: Diagnóstico y remedio", en Revista Española de Investigación Criminológica, 2008, n. ${ }^{\circ}$ 6, págs. 1- 31.

DÍAZ-MAROTO Y VILLAREJO, Julio: "Prólogo a la presente edición", en Código penal y legislación complementaria, $36{ }^{\mathrm{a}}{ }^{\mathrm{e}} \mathrm{ed}$. a cargo de J. DíazMaroto. Civitas/ Thomson Reuters, Madrid, 2010, págs. 19 - 22.

DÍEZ RIPOLLÉS, José Luis: "El nuevo modelo penal de la seguridad ciudadana", en Revista Electrónica de Ciencia Penal y Criminología, 2004, 06-03, págs. 1- 34

DÍEZ RIPOLLÉS, José Luis: "La nueva política criminal española”, en Cuadernos penales José María Lidón, 2004 (n. ${ }^{\circ}$ 1), págs. 11 - 38.

DÍEZ RIPOLLÉS, José Luis: "De la sociedad del riesgo a la seguridad ciudadana: un debate desenfocado", Revista Electrónica de Ciencia Penal y Criminología, 2005, 07-01, págs. 1 - 37.

DÍEZ RIPOLLÉS, José Luis: La política criminal en la encrucijada. Ed BdF, Buenos Aires - Montevideo, 2007.

FUENTES OSORIO, Juan L: "Los medios de comunicación y el Derecho penal", en Revista Electrónica de Ciencia Penal y Criminología (http://criminet.uigr.es) 2005 (16), págs. $1-51$.

GABINETE DE ESTUDIOS DE SEGURIDAD INTERIOR (Secretaría de Estado de Seguridad, Ministerio del Interior): Junio 2010. Evolución de la criminalidad. Ámbito de actuación del Cuerpo Nacional de Policía y de la Guardia Civil. Junio 2010: evolución de la criminalidad durante los últimos 12 meses, en www.mir.es, set. 2010, págs. 1 - 23.

GALLEGO DÍAZ, Manuel / CABRERA CABRERA, Pedro José./ RÍOS MARTÍN, Julián Carlos / SEGOVIA BERNABÉ, José Luis: Andar $l \mathrm{~km}$ en línea recta. La cárcel del siglo XXI que vive el preso. U. Pontificia de Comillas. Madrid. 2010.

GARCÍA ARÁN, Mercedes/ PERES-NETO, Luiz: "Discursos mediáticos y reformas penales", en GARCÍA ARÁN, Mercedes / BOTELLA CORRAL, Joan (Dirs.), Malas noticias. Medios de comunicación, política criminal y garantías penales en España. Tirant lo Blanch, Valencia, 2008, págs. 153-189.

GARCÍA ESPAÑA, Elisa/ DÍEZ RIPOLLÉS, José Luis/ PÉREZ JIMÉNEZ, Fátima/ BENÍTEZ JIMÉNEZ, María José/ CEREZO DOMÍNGUEZ, María José: "Evolución de la delincuencia en España: Análisis longitu- 
dinal con encuestas de victimización", en Revista Española de Investigación Criminológica, 2010 (n. ${ }^{\circ} 8$, artículo 2), págs. $1-27$.

GARCÍA RIVAS, Nicolás/ LAMARCA PÉREZ, Carmen: "Organizaciones y grupos criminales”, en ÁLVAREZ GARCÍA, Francisco Javier/ GONZÂLEZ CUSSAC, José Luis (Dirs.): Comentarios a la reforma penal de 2010. Tirant lo Blanch, Valencia, 2010, págs. $503-520$.

GIMBERNAT ORDEIG, Enrique: "Prólogo a la decimosexta edición", en Código penal, Ed. Tecnos, 16. ${ }^{\mathrm{a}}$ ed., Madrid, 2010, pág.17.

GIMÉNEZ-SALINAS FRAMIS, Andrea/ CORTE IBANEZ, Luis de la / REQUENA ESPADA, Laura/ JUAN ESPINOSA, Manuel de:'La medición y evaluación de la criminalidad organizada en España: ¿Misión imposible?", en Revista Española de Investigación Criminológica, 2009 (n. ${ }^{\circ} 7$; artículo 9), págs. 1 - 28.

GONZÁLEZ CUSSAC, José L.: "La contrarreforma penal de 2003: Nueva y vieja política criminal”, en Revista Xuridica Galega, 2003 (n. ${ }^{\circ} 38$ ), págs. 13 - 38.

GONZÁLEZ CUSSAC, José Luis: "La reforma permanente: clima de miedo, pensamiento impecable y derechos mínimos", en ÁLVAREZ GARCÍA, Francisco Javier/ GONZÁLEZ CUSSAC, José Luis (Dirs.): Comentarios a la reforma penal de 2010. Tirant lo Blanch, Valencia, 2010, págs. $39-44$.

GONZÁLEZ TASCON, María Marta: "El periodo de seguridad (art. 36.2)", en ÁLVAREZ GARCÍA, Francisco Javier/ GONZÁLEZ CUSSAC, José Luis (Dirs.): Comentarios a la reforma penal de 2010. Tirant lo Blanch, Valencia, 2010, págs. 91 - 94.

GONZÁLEZ TASCON, María Marta: "La pena de localización permanente (art. 37)", en ÁLVAREZ GARCÍA, Francisco Javier/ GONZÁLEZ CUSSAC, José Luis (Dirs.): Comentarios a la reforma penal de 2010. Tirant lo Blanch, Valencia, 2010, págs. 95 - 99.

GRUPO "Otro Derecho penal es posible": Mitos del Derecho penal, en http:/www.otroderechopenal.com (última consulta, octubre 2010).

JAKOBS, Günther: La ciencia del derecho penal ante las exigencias del presente. Universidad del Externado de Colombia. Bogotá. 2000.

JAKOBS, Günther: "Derecho penal del ciudadano y derecho penal del enemigo", en JAKOBS, Günther/ CANCIO MELIÁ, Manuel: Derecho penal del enemigo. Thomson-Civitas. Madrid, 2003, págs. 19 - 56.

JIMÉNEZ DÍAZ, María José: Seguridad ciudadana y Derecho penal. Dykinson, Madrid, 2006.

LANDROVE DÍAZ, Gerardo: "El Derecho penal «de la seguridad»", en $L a$ Ley, 2003-4, págs. 1923 - 1932.

LANDROVE DÍAZ, Gerardo: El nuevo derecho penal. Tirant lo Blanch, Valencia, 2009.

LARRAURI PIJOAN, Elena: "La economía política del castigo", en Revista Electrónica de Ciencia Penal y Criminología, 2009 (n. ${ }^{\circ} 11$ ), págs. 1 22 (http://criminet.ugr.es). 
LUZÓN PEÑA, Diego-Manuel/ DÍAZ Y GARCÍA CONLLEDO, Miguel/ VICENTE REMESAL, Javier de/ PAREDES CASTAÑÓN, José Manuel/ OLAIZOLA NOGALES, Inés: "Prólogo a la edición de 2010", en Código penal. La Ley, Madrid, 2010, págs. 5 - 7.

MAQUEDA ABREU, María Luisa: "Crítica a la reforma penal anunciada", en Jueces para la Democracia, 2003 (n. ${ }^{\circ}$ 47), págs. 6 - 11.

MARTELL PÉREZ-ALCALDE, Cristóbal/ QUINTERO GARCÍA, Débora: "De las organizaciones y grupos criminales (arts. 570 bis, 570 ter 570 quáter)", en QUINTERO OLIVARES, G., La Reforma Penal de 2010: Análisis y Comentarios. Aranzadi / Thomson Reuters, Cizur Menor,2010, págs. 356 - 367.

MATA BARRANCO, Norberto de la: "Las reformas penales de 2003: consideraciones generales sobre la quiebra de algunos principios que deben definir toda intervención penal", en FARALDO CABANA, Patricia, Política criminal y reformas penales. Tirant lo Blanch, Valencia, 2007, págs. $11-34$.

MENDOZA BUERGO, Blanca: "Gestión del riesgo y política criminal de seguridad en la sociedad del riesgo", en AGRA, Cândido da et $a l$., $L a$ seguridad en la sociedad del riesgo. Un debate abierto. Atelier, Barcelona, 2003, págs. $67-89$.

MESTRE DELGADO, Esteban: "Código penal nuevo y obsoleto", en $L a$ Ley penal, "Una nueva reforma del Código Penal", 2010 ( julio), págs. 5 -10 .

MUÑOZ CONDE, Francisco: "Prólogo" a LANDROVE DÍAZ, Gerardo: El nuevo derecho penal. Tirant lo Blanch, Valencia, 2009, "págs. 11 - 15.

MUÑOZ CONDE, Francisco: Derecho Penal. Parte Especial. 18. ed. Tirant lo Blanch, Valencia, 2010.

MUÑOZ CONDE, Francisco: "Prólogo", a LANDROVE DÍAZ, Gerardo: $E l$ nuevo derecho penal. Tirant lo Blanch, Valencia, 2010, págs. $11-15$.

PAREDES CASTAÑÓN, José Manuel: "La seguridad como objetivo político-criminal del sistema penal", en Eguzkilore, 2006 (n. ${ }^{\circ} 20$ ), págs. 129 149.

PÉREZ CEPEDA, Ana Isabel: "El paradigma de la seguridad en la globalización: guerra, enemigos y orden penal”, en GARCÍA RIVAS, Nicolás et al.: El Derecho penal frente a la inseguridad global. Ed. Bomarzo, Albacete, 2007, págs. 85 - 122.

QUINTERO OLIVARES, Gonzalo: "Estudio preliminar: cambiar las leyes y cambiar el Derecho Penal. Sobre la última reforma del Código penal", en QUINTERO OLIVARES, G., La Reforma Penal de 2010: Análisis y Comentarios. Aranzadi / Thomson Reuters, Cizur Menor,2010, págs. 15 $-26$.

ROBLES PLANAS, Ricard: "Violencia y seguridad", en Revista Electrónica de Ciencia Penal y Criminología, 2004 (n. ${ }^{\circ}$ 06-rl), págs. 1 - 3. 
SANZ MORÁN, Ángel José: "Reflexiones de urgencia sobre las últimas reformas de la legislación penal", en Revista de Derecho Penal, 2004 (n. ${ }^{\circ}$ 11), págs. $11-40$.

SERRANO GÓMEZ, Alfonso: "Legislación líquida. Una nota sobre el Proyecto de Ley de 2009 de Reforma del Código Penal", en Revista Electrónica de Ciencia Penal y Criminología, 2010 (n. ${ }^{\circ}$ 12), págs. 1 - 7 (http://criminet.ugr.es).

SILVA SÁNCHEZ, Jesús-María: "El retorno de la inocuización. El caso de las reacciones jurídico-penales frente a los delincuentes sexuales violentos", en NIETO, Adán (Coord.), Homenaje al Dr. Marino Barbero Santos. In memoriam. Vol I. Ed. U. de Castilla - La Mancha /Ed. U. de Salamanca, 2001, págs. $699-710$.

SILVA SÁNCHEZ, Jesús-María: La expansión del Derecho penal. Aspectos de la política criminal en las sociedades postindustriales. 2. ${ }^{\mathrm{a}} \mathrm{ed}$. Ed. IB de F. Montevideo - Buenos Aires. 2006.

SILVA SÁNCHEZ, Jesús-María: "El contexto del Anteproyecto de Reforma del Código Penal de 2008", en Cuadernos penales José María Lidón, 2009 (n. ${ }^{\circ}$ ), págs. $15-34$.

SILVA SÁNCHEZ, Jesús-María: "La reforma del Código penal: una aproximación desde el contexto", en La Ley, 9/9/2010 (n. ${ }^{\circ}$ 7464), págs. 1 - 7.

SILVA SÁNCHEZ, Jesús-María / FELIP I SABORIT, David / ROBLES PLANAS, Ricardo / PASTOR MUÑOZ, Nuria: "La ideología de la seguridad en la legislación penal", en AGRA, Cândido da et al., La seguridad en la sociedad del riesgo. Un debate abierto, Atelier, Barcelona, 2003, págs. 113 - 135.

SOTO NAVARRO, Susana: "La influencia de los medios en la percepción social de la delincuencia", en Revista Electrónica de Ciencia Penal y Criminología (http://criminet.uigr.es) 2005 (9), págs. 1 - 46.

TORRES ROSELL, Nuria: "La pena de localización permanente y la pena de trabajos en beneficio de la comunidad", en QUINTERO OLIVARES, G., La Reforma Penal de 2010: Análisis y Comentarios. Aranzadi / Thomson Reuters, Cizur Menor, 2010, págs. 91- 97.

ZÚÑIGA RODRÍGUEZ, Laura: "Viejas y nuevas tendencias político criminales en las legislaciones penales", en BERDUGO GÓMEZ DE LA TORRE, Ignacio/ SANZ MULAS, Nieves, Derecho Penal de la Democracia vs Seguridad Pública. Ed. Comares. Granada, 2004, págs. 98 129.

VIVES ANTÓN, Tomás S.: “¿Estado democrático o estado autoritario? (Reflexiones jurídico-políticas a propósito de un Anteproyecto de Código Penal", en Teoría y Derecho. Revista de Pensamiento Jurídico, 2008 (n. ${ }^{\circ}$ ), págs. $264-273$. 